\title{
Calcium-regulatory proteins as modulators of chemotherapy in human neuroblastoma
}

\author{
Ana-Maria Florea ${ }^{1}$, Elizabeth Varghese ${ }^{2}$, Jennifer E. McCallum ${ }^{2}$, Safa Mahgoub ${ }^{2}$, \\ Irfan Helmy ${ }^{2}$, Sharon Varghese ${ }^{2}$, Neha Gopinath ${ }^{2}$, Steffen Sass ${ }^{3}$, Fabian J. Theis ${ }^{3}$, \\ Guido Reifenberger ${ }^{1}$, Dietrich Büsselberg ${ }^{2}$ \\ ${ }^{1}$ Institute of Neuropathology, Heinrich Heine University Düsseldorf, Düsseldorf, Germany \\ ${ }^{2}$ Weill Cornell Medicine in Qatar, Qatar Foundation-Education City, Doha, Qatar \\ ${ }^{3}$ Institute of Computational Biology, Helmholtz Zentrum München, Neuherberg, Germany \\ Correspondence to: Ana-Maria Florea, email: anamflorea@gmail.com \\ Keywords: neuroblastoma, cisplatin, topotecan, calcium signaling, chemotherapy \\ Received: September 20, $2016 \quad$ Accepted: January 27, $2017 \quad$ Published: February 11, 2017
}

\section{ABSTRACT}

Neuroblastoma (NB) is a pediatric cancer treated with poly-chemotherapy including platinum complexes (e.g. cisplatin (CDDP), carboplatin), DNA alkylating agents, and topoisomerase I inhibitors (e.g. topotecan (TOPO)). Despite aggressive treatment, NB may become resistant to chemotherapy. We investigated whether CDDP and TOPO treatment of NB cells interacts with the expression and function of proteins involved in regulating calcium signaling. Human neuroblastoma cell lines SH-SY5Y, IMR-32 and NLF were used to investigate the effects of CDDP and TOPO on cell viability, apoptosis, calcium homeostasis, and expression of selected proteins regulating intracellular calcium concentration $\left(\left[\mathrm{Ca}^{2+}\right]_{i}\right)$. In addition, the impact of pharmacological inhibition of $\left[\mathrm{Ca}^{2+}\right]_{i}$-regulating proteins on neuroblastoma cell survival was studied. Treatment of neuroblastoma cells with increasing concentrations of CDDP $(0.1-10 \mu \mathrm{M})$ or TOPO $(0.1 \mathrm{nM}-1 \mu \mathrm{M})$ induced cytotoxicity and increased apoptosis in a concentration- and time-dependent manner. Both drugs increased $\left[\mathrm{Ca}^{2+}\right]_{\mathrm{i}}$ over time. Treatment with CDDP or TOPO also modified mRNA expression of selected genes encoding $\left[\mathrm{Ca}^{2+}\right]_{i}$-regulating proteins. Differentially regulated genes included S1O0A6, ITPR1, ITPR3, RYR1 and RYR3. With FACS and confocal laser scanning microscopy experiments we validated their differential expression at the protein level. Importantly, treatment of neuroblastoma cells with pharmacological modulators of $\left[\mathrm{Ca}^{2+}\right]_{i}$-regulating proteins in combination with CDDP or TOPO increased cytotoxicity. Thus, our results confirm an important role of calcium signaling in the response of neuroblastoma cells to chemotherapy and suggest $\left[\mathrm{Ca}^{2+}\right]_{i}$ modulation as a promising strategy for adjunctive treatment.

\section{INTRODUCTION}

Neuroblastoma (NB) accounts for approximately 7\% of pediatric malignancies and is responsible for more than $10 \%$ of cancer-related mortality in children [1]. Prognosis and treatment are determined by clinical and biological risk factors [2]. Estimated 5-year survival of patients with high-risk NB is less than $50 \%$, despite receiving multimodal and highly aggressive treatment schemes that include surgery, high-dose polychemotherapy and radiation, as well as myeloablative treatment and immunetherapy [1].
Despite chemotherapy dose intensification, approximately $20 \%$ of neuroblastoma patients show an inadequate response to induction therapy and/ or experience disease progression following initial therapy. Standard North American Children Oncology Group (COG) induction regimens include combinations of anthracyclines, DNA alkylating agents, platinum compounds and topoisomerase II inhibitors delivered every 21 days for 5 to 7 cycles. The International Society of Pediatric Oncology Europe Neuroblastoma uses a more rapid regimen in which cycles are delivered every 10 days and that demonstrated superior 5-year event-free 
survival of $30 \%$, compared with $18 \%$ for standard interval chemotherapy $[1,3]$. Furthermore, the topoisomerase I inhibitor topotecan has demonstrated efficacy in recurrent $\mathrm{NB}$ and has recently been incorporated into the COG induction regimens $[4,1]$. Both, cisplatin and topotecan are currently used in the treatment of patients with recurrent neuroblastoma $[1,3,4]$.

Calcium signaling controls physiologic and pathologic cellular processes. Intracellular $\mathrm{Ca}^{2+}$ is a universal second messenger whose concentration $\left(\left[\mathrm{Ca}^{2+}\right]_{\mathrm{i}}\right)$ is precisely regulated. A considerable body of evidence demonstrates that changes in the expression or function of $\left[\mathrm{Ca}^{2+}\right]_{i}$-regulating proteins (channels or active transport proteins) deregulate $\left[\mathrm{Ca}^{2+}\right]_{\mathrm{i}}$, which in turn may cause perturbation of important signaling pathways that govern cell homeostasis. Several anti-cancer drugs, including cisplatin (CDDP), have been shown to modulate $\left[\mathrm{Ca}^{2+}\right]_{\text {. }}$ in cancer cells, triggering calcium-dependent cell death via apoptosis $[5,6,7]$. Nevertheless, the mechanisms by which $\left[\mathrm{Ca}^{2+}\right]_{\mathrm{i}}$ is elevated depend on the drug used. For example, CDDP and arsenic trioxide $\left(\mathrm{As}_{2} \mathrm{O}_{3}\right)$ strongly elevate $\left[\mathrm{Ca}^{2+}\right]$ and enhance apoptosis of tumor cells. However, the two drugs elevate $\left[\mathrm{Ca}^{2+}\right]_{\mathrm{i}}$ via different mechanism. Whilst CDDP induces extracellular $\mathrm{Ca}^{2+}$ uptake into the cytosol, with $\mathrm{Ca}^{2+}$ then being pumped into the calcium stores of the cells [5], $\mathrm{As}_{2} \mathrm{O}_{3}$ triggers a $\mathrm{Ca}^{2+}$ release from intracellular stores [8,9]; for review see [10]. Therefore, a combination of different anticancer drugs that rise $\left[\mathrm{Ca}^{2+}\right]_{\mathrm{i}}$ by different mechanisms may improve efficiency of induced tumor cell death, For e.g. this was shown in neuroblastoma cells by treating cell cultures first with CDDP, triggering $\mathrm{Ca}^{2+}$ uptake and intracellular storage of $\mathrm{Ca}^{2+}$, followed by application of $\mathrm{As}_{2} \mathrm{O}_{3}$ that led to an abrupt release of $\mathrm{Ca}^{2+}$ from the intracellular stores [11].

Microarray and quantitative real-time PCR (qRT-PCR) analyses in combination with bioinformatics approaches can determine gene expression profiles that may elucidate the cellular response to anticancer drugs and identify gene signatures that may predict the development of drug resistance. For instance, gene expression profiling studies have revealed distinct gene expression signatures in neuroblastoma tissue samples linking the expression of several calcium signalingassociated genes to patient prognosis [12]. In the microarray-based Neuroblastoma Database reported by Chen and colleagues (2008) [12], the authors identified genetic signatures of 160 top-regulated genes linked to patient prognosis [12]. In addition, genes associated with mitochondria, cell metabolism and cell cycle were highlighted as potential therapeutic targets [12]. In another study, the importance of alternative splicing following high-level amplification of the $M Y C N$ gene in neuroblastoma has been explored [13].

In this study we investigated changes in expression of selected genes whose gene products are directly linked to the regulation of calcium dynamics in established neuroblastoma cell line models following treatment with the clinically important drugs CDDP and topotecan. We used database interrogation of the microarray-based Neuroblastoma Database [12] to identify and select a limited number of potential $\left[\mathrm{Ca}^{2+}\right]_{i}$ signaling-related molecules that might be of relevance in neuroblastoma, including inositol triphosphate receptors I and III (ITPRI, $I T P R 3)$, ryanodine receptors 1 and 3 (RYR1, RYR3), and the S100 calcium-binding protein A6 (S100A6). To determine the relationship between gene expression and function of these selected $\left[\mathrm{Ca}^{2+}\right]_{i}$ signaling regulators in the drug sensitivity of neuroblastoma cells, we incorporated cytotoxicity and apoptosis assays, live-cell calcium imaging, gene and protein expression analyses and functional assays.

\section{RESULTS}

\section{CDDP and TOPO decrease viability of neuroblastoma cells in a time- and concentration- dependent manner}

In human neuroblastoma cell lines we tested the sensitivity to cisplatin (CDDP) and topotecan (TOPO) (Figure 1A and 1B). CDDP and TOPO triggered cell toxicity in a concentration- and time-dependent manner. A significant decrease of cell viability was observed after $48 \mathrm{~h}$ of exposure of SH-SY5Y cells to $10 \mu \mathrm{M}$ CDDP and after $72 \mathrm{~h}$ exposure of SH-SY5Y cells to 1 and $10 \mu \mathrm{M}$ CDDP $(p<0.01 ; p<0.001)$ (Figure 1Ai). IMR-32 neuroblastoma cells were more sensitive to CDDP, showing a significant decrease in cell viability after treatment with $10 \mu \mathrm{M}$ CDDP for $24 \mathrm{~h}(p<0.05)$; 1 and $10 \mu \mathrm{M}$ CDDP for $48 \mathrm{~h}(p<0.05$ and $p<0.001)$ and $72 \mathrm{~h}(p<0.001$ and $p<0.001)$ (Figure 1Bi). A third neuroblastoma cell line, NLF, was less sensitive to CDDP, i.e., demonstrated a significant decrease in cell viability only after $48 \mathrm{~h}$ treatment with $10 \mu \mathrm{M}$ CDDP $(p<0.001$; Supplementary Figure 1).

TOPO $(0.1 \mathrm{nM}$ to $1 \mu \mathrm{M})$ demonstrated a stronger cytotoxic effect compared to CDDP in all neuroblastoma cell lines tested and cell viability was significantly reduced in SH-SY5Y cell after $24 \mathrm{~h}, 48 \mathrm{~h}$ and $72 \mathrm{~h}$ of exposure (Figure 1Ai). The cytotoxic effects of TOPO were stronger in IMR-32 cells as compared with SH-SY5Y and NLF cells (Figure 1Ai and 1Bi) (Supplementary Figure 1).

\section{CDDP and TOPO trigger cell death, mainly by apoptosis, in a time- and concentration-dependent manner}

Neuroblastoma cells treated with CDDP and TOPO showed significantly increased apoptotic and necrotic cell populations, clearly visible in the fluorescently gated representative scatter plots for SH-SY5Y (Figure 1Aii) and IMR-32 (Figure 1Bii). 
The cell populations measured by FACS following $72 \mathrm{~h}$ of drug exposure demonstrated that the predominant mechanism of cell death was apoptosis. Measurements showed that apoptotic and necrotic cell population's increased significantly with $\geq 1 \mu \mathrm{M}$ CDDP or $\geq 0.01 \mu \mathrm{M}$ TOPO for both SH-SY5Y and IMR-32 cells (Figure 1Ci and 1Cii).

Both cell lines exhibited similar increases in apoptotic cell fractions following exposure to either drug, with a concomitant decrease in vital cell populations $(p<0.001)$. TOPO was more efficient than CDDP in inducing apoptosis in both cell lines, compared to CDDP: concentrations as low as $0.001 \mu \mathrm{M}$ of TOPO were sufficient to significantly increase cell death by apoptosis in both SH-SY5Y and IMR-32 cells (Figure 1Ci and 1Cii).

\section{$\left[\mathrm{Ca}^{2+}\right]_{i}$ increased time- and concentration- dependently with the application of CDDP or TOPO}

Individual (but not all) neuroblastoma cells increased $\left[\mathrm{Ca}^{2+}\right]_{i}$ time- and concentration-dependently following application of either CDDP or TOPO (0.01 $\mu \mathrm{M}-1 \mu \mathrm{M})$. Table 1 outlines the percentage of responding cells following exposure to increasing drug concentrations. Figure 2A shows representative examples of individually selected cells/ROIs increasing in fluorescence intensity over time. Only responding cells were used to analyze the increase in $\left[\mathrm{Ca}^{2+}\right]_{\mathrm{i}}$ (Figure 2B, statistics shown in Supplementary Files). In both SH-SY5Y and IMR-32 cells, $\left[\mathrm{Ca}^{2+}\right]_{\mathrm{i}}$ increased following drug exposure, reaching a steady state after $1-3 \mathrm{~h}$.

Averaged data from at least three independent applications per concentration are illustrated in Figure 2B. There was a clear time-dependent effect of CDDP on SHSY5Y cells concerning $\left[\mathrm{Ca}^{2+}\right]_{\mathrm{i}}$. However, a concentration of $0.01 \mu \mathrm{M}$ was more effective than higher concentrations tested in this experimental setup. The rise of $\left[\mathrm{Ca}^{2+}\right]_{i}$ was higher in IMR-32 cells than in SH-SY5Y cells following CDDP but not TOPO treatment (Figure 2B). For CDDP, this finding was mirrored by a higher sensitivity in apoptosis assays (Figure 1A and 1B). Treatment of IMR-32 cells with TOPO induced a smaller increase of $\left[\mathrm{Ca}^{2+}\right]_{i}$ (Figure 2B).

\section{CDDP and TOPO deregulate mRNA expression of genes encoding $\left[\mathrm{Ca}^{2+}\right]_{i}$-regulators}

Next, we investigated whether the mRNA expression of selected genes encoding regulators of $\left[\mathrm{Ca}^{2+}\right]_{1}$ (Figure 3 and Supplementary Figures 2-3) changed following exposure to CDDP (Figure 3A) or TOPO (Figure 3B) in SH-SY5Y and in IMR-32 cells (Figure $3 \mathrm{C})$. qRT-PCR analysis indicated that $\mathrm{mRNA}$ expression of S100A6 in SH-SY5Y cells increased with treatment of either drug (Figure 3A). This increase was paralleled by up-regulation of $\mathrm{COX} 2 \mathrm{mRNA}$ expression in SH-SY5Y cells treated with CDDP and TOPO (Figure 3). This was also true for IMR-32 cells exposed to CDDP $(p<0.001)$ (Figure 3C). The increase of COX2 mRNA expression showed similar dynamics for CDDP and TOPO treatment, i.e., up-regulation of $C O X 2$ mRNA peaked at $48 \mathrm{~h}$ exposure, followed by a marked decrease in expression after $72 \mathrm{~h}$ (Figure 3A and 3B).

Investigation of IMR-32 cells revealed that CDDP (Figure 3C) or TOPO (Supplementary Figure 3) treatment also triggered an up-regulation of S100A6 and COX2 mRNA expression, thus confirming the findings with SH-SY5Y cells (Figure 3C and Supplementary Figure 3). Similarly, CDDP treatment of NLF cells caused increased expression of both transcripts (Supplementary Figure 3). For $72 \mathrm{~h}$ CDDP treatment, the increase in mRNA expression of $5100 A 6$ was 8-10-fold higher compared to control conditions in all three cell lines tested $(p<0.001)$ (Figure 3A and 3C, Supplementary Figure 3). Following TOPO treatment, this increase was the strongest in SHSY5Y (Figure 3B) followed by IMR-32 (Supplementary Figure 3) and NLF cells (data not shown).

Changes in expression of ITPR 1, ITPR 3, RYR 1 and $R Y R 3$ transcripts upon treatment with CDDP or TOPO were also assessed and results indicated that RYR 1 and $R Y R 3$ were both deregulated at the mRNA level in SH-SY5Y cells (Figure 3A and 3B). Expression of ITPRI and $I T P R 3$ transcripts was as well deregulated in SH-SY5Y neuroblastoma cells upon treatment with CDDP or TOPO (Figure $3 \mathrm{~A}$ and $3 \mathrm{~B}$ ) this effect was also observed for both treatments in IMR-32 cells (Figure 3C and Supplementary Figure 3) and for CDDP treatment in NLF cells (Supplementary Figure 3).

\section{Expression of essential $\left[\mathrm{Ca}^{2+}\right]_{-}$-regulating proteins following CDDP or TOPO treatment}

The expression of the selected proteins was performed using FACS and confocal microscopy (Figures 4, 5, Table 2). FACS analysis in SH-SY5Y cells revealed significant increases in the expression of selective isoforms of IP3 and ryanodine receptors, specifically IP3R3 and RYR3, following treatment with CDDP at $1 \mu \mathrm{M}$ or $10 \mu \mathrm{M}(p<0.001)$ (Figure $4 \mathrm{~A})$.

A significant increase in expression in the calciumbinding protein S100A6 was also evident at these concentrations $(p<0.01)$ (Figure $4 \mathrm{~A})$. We detected no significant changes in the expression levels of either RYR1 or RYR3 receptors following treatment with TOPO (Figure 4B). Expression of IP3R3 and S100A6 proteins was increased to higher levels following exposure to an increased concentration of $0.1 \mu \mathrm{M}$ when compared to $0.01 \mu \mathrm{M}$ TOPO (Figure 4B). In contrast, higher concentrations of CDDP did not demonstrate a stronger effect on protein expression levels (Figure 4A). This was also investigated in IMR-32 cells (Supplementary 
A i)
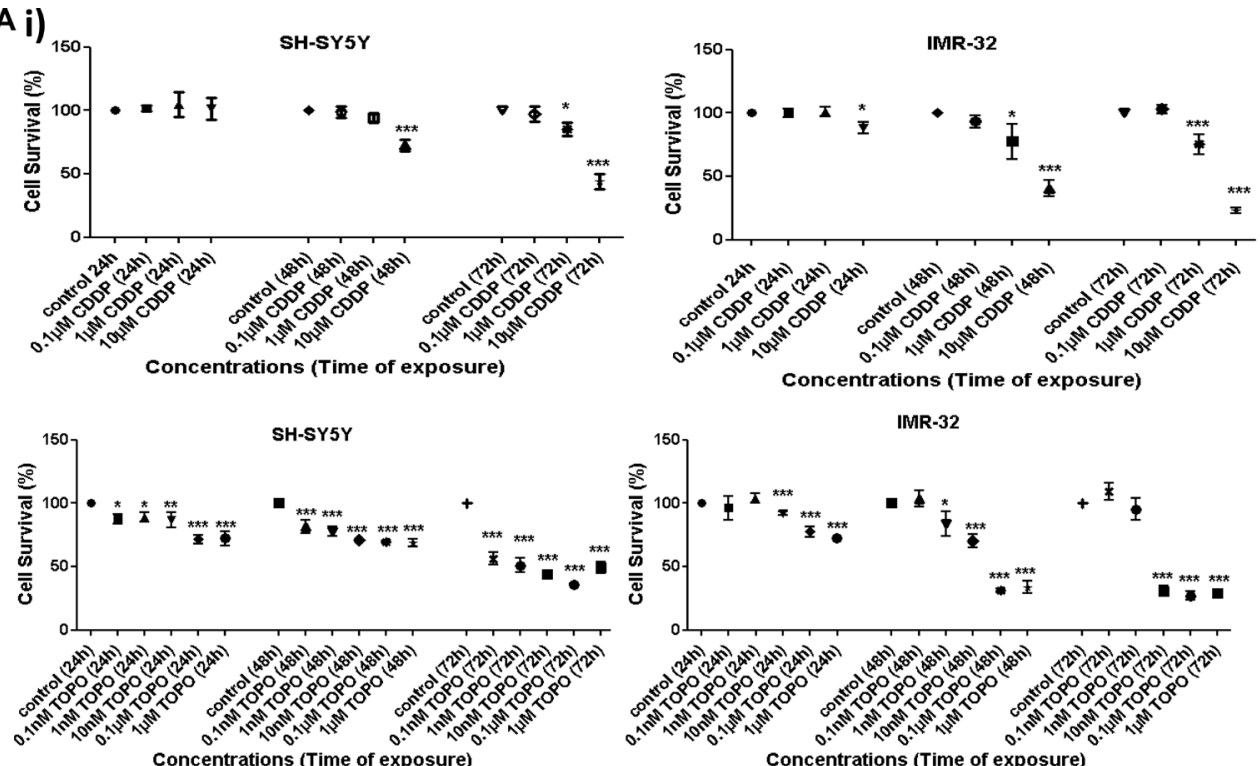

Bi)

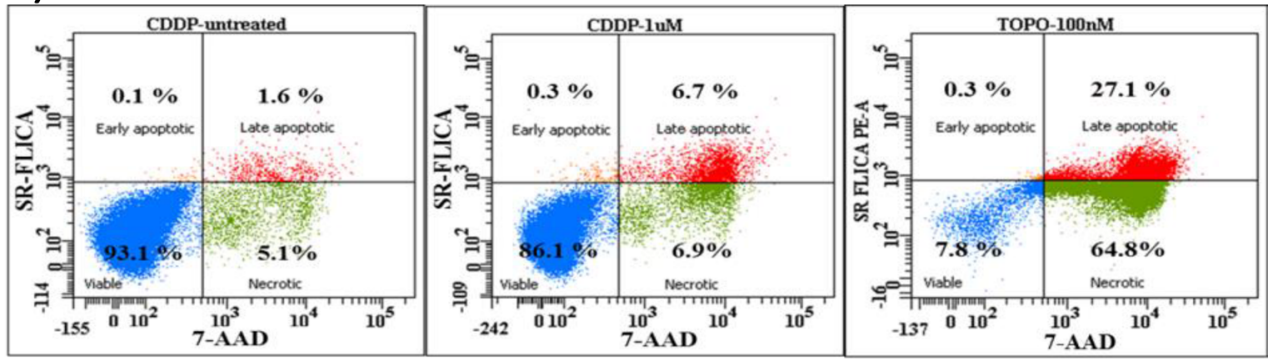

ii)
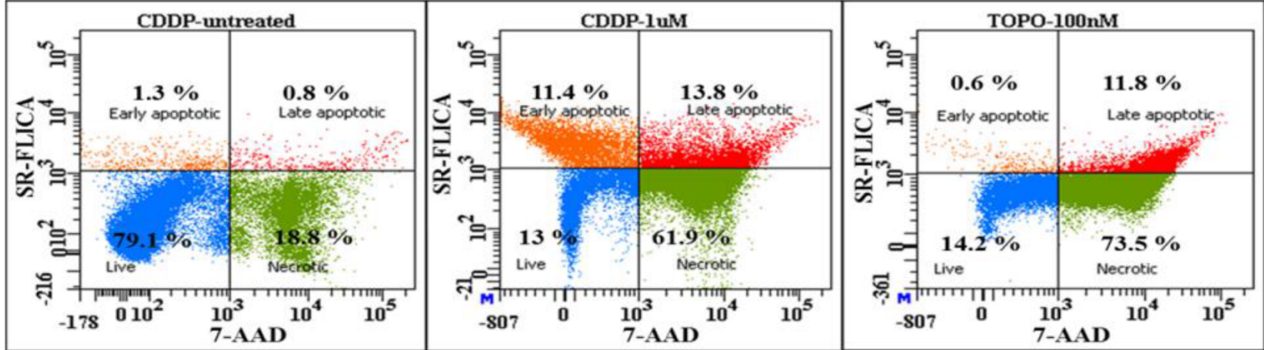

ci)
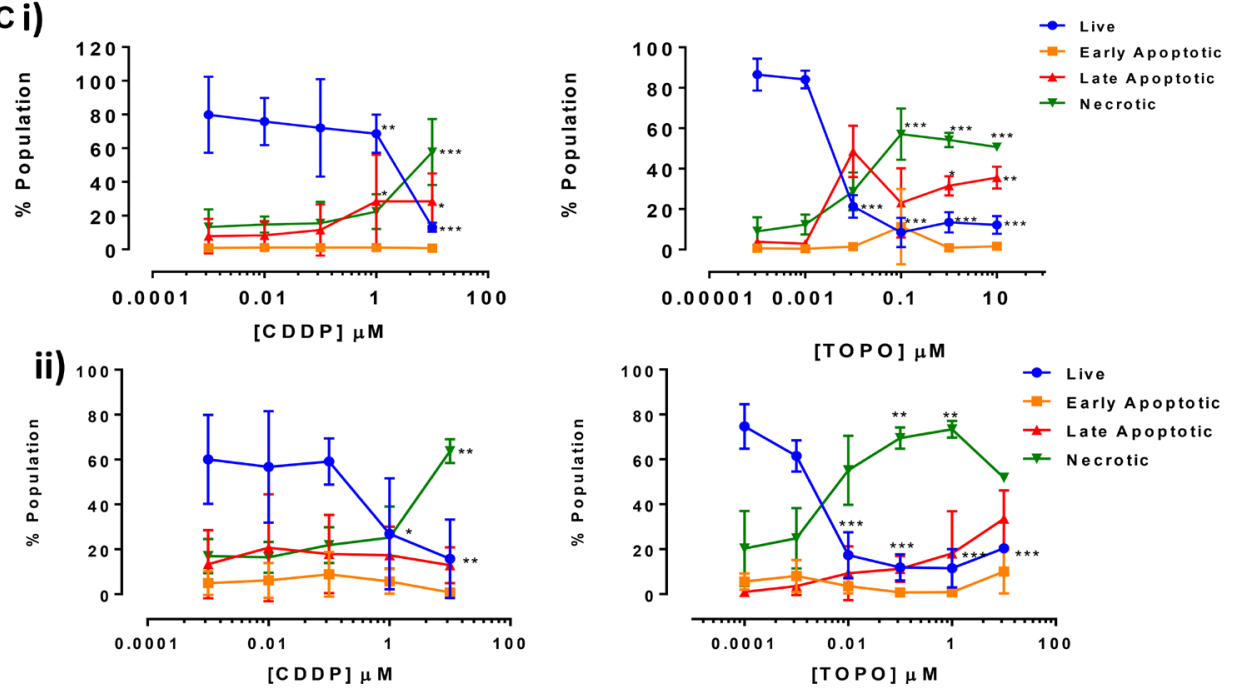
Figure 1: Cell survival and apoptosis in neuroblastoma cells following CDDP or TOPO treatment. (A) Cell survival detected by the trypan blue exclusion test following exposure to $0.1 \mu \mathrm{M}-10 \mu \mathrm{M}$ CDDP and $0.1 \mathrm{nM}-1 \mu \mathrm{M}$ TOPO for 24,48 and $72 \mathrm{~h}$ in SH-SY5Y (i) and IMR-32 cells (ii). Shown are three independent experiments each $(n=3)$. (B) Examples of representative scatter plots outlining the population distributions (live, early apoptotic, late apoptotic and necrotic) of untreated, CDDP-treated (1 $\mu \mathrm{M})$ and TOPOtreated (100 nM) SH-SY5Y (i) and IMR-32 (ii) cells as detected by FACS analysis following $72 \mathrm{~h}$ of drug exposure using a total cytotoxicity kit with fluorescent markers 7-amino actinomycin D (7-AAD) and sulforhodamine flurochrome labeled inhibitors of apoptosis (SR-FLICA) (ImmunoChemistry Technologies). (C) Quantification of cell apoptosis and necrosis via FACS analysis in SH-SY5Y (i) and IMR-32 (ii) cells incubated with different concentrations of CDDP $(0.001 \mu \mathrm{M}-10 \mu \mathrm{M})$ or TOPO $(100 \mathrm{pM}-10 \mu \mathrm{M})$ at $72 \mathrm{~h}$. Shown are three independent experiments each $(n=3)$. Statistical significance is relative to untreated v's treated conditions and is considered if $p<0.05(*), p<0.01(* *)$, $p<0.001(* * *)$ when assessed via a One-Way ANOVA (C) and Two-Way ANOVA (A) tests with Dunnett's Test for multiple comparisons.

Figure 4) that confirmed the up-regulation of S100A6; IP3R3 and RYR3 but showed no down-regulation of RYR1 in CDDP treated neuroblastoma cells (Supplementary Figure 4).

To confirm the results obtained by FACS analysis, we investigated the changes in the expression level of inositol trisphosphate receptors 1 and 3 (IP3R1, IP3R3), ryanodine receptors 1 and 3 (RYR1, RYR3) and the calcium-binding protein S100A6 in SH-SY5Y following treatment with CDDP or TOPO via confocal microscopy (Figure 5). In order to perform quantitative confocal analysis experiments lower drug concentrations ranging 0.01-1 $\mu \mathrm{M}$ were used for image acquirement and quantification of the protein expression since higher concentrations of chemotherapeutic agents induced cytotoxicity (Figure 5A).

The variable patterns of expression of the investigated proteins are demonstrated in Figure 5A and further highlighted in the quantification profiles of basal expression in Figure 5B. RYR1 and S100A6 proteins were expressed at very low levels, a finding in line with the FACS results showing basal levels of $<20 \%$ and $<30 \%$ positive cells, respectively (Figure 4).

IP3R3 and RYR3 were found to be most robustly expressed amongst the investigated proteins and this was also in agreement with the FACS results, demonstrating basal levels in excess of $60 \%$ positive fluorescence intensity for both proteins (Figures 4 and 5). Importantly, the quantification of expression confirmed increased protein expression levels of IP3R3 and S100A6 following treatment with low concentrations of either CDDP or TOPO. However we could not determine a significant increase in the protein expression of RYR3, that was shown with FACS experiments, while, in line with the respective mRNA data (Figure 3A), an increase of protein expression of RYR1 was determined in the confocal microscopy experiments following treatment with low concentrations of either CDDP or TOPO (Figure 5B and Table 2), as opposed to the respective FACS results (Figure 4B).

\section{Microarray analysis reflects the calcium- dependent activation of signaling pathways involved in p53 signaling, cell cycle control and RNA transport}

We next checked whether calcium-dependent signaling in SH-SY5Y is changed upon treatment with
$10 \mu \mathrm{M}$ CDDP for $72 \mathrm{~h}$ using microarray-based expression profiling (See Supplementary Figure 9 and Supplementary File 1 for complete deregulated gene list). Principal component analysis revealed a clear separation of untreated (control) cells and CDDP-treated cells (See Supplementary Figure 9). Bioinformatic evaluation of the microarray data including Gene Ontology term and KEGG pathway analysis using the RAMONA software [14] confirmed that several genes involved in calcium signaling were deregulated upon CDDP treatment (Supplementary Files 2 and 3). Furthermore, exposure to CDDP deregulated several other signaling pathways including: (i) KEGG pathways - purine metabolism, p53 signaling, RNA transport, cell cycle regulation as well as caspase 8 / caspase 3-dependent apoptosis as well as (ii) GO terms - mitotic cell cycle, ncRNA metabolic process, organonitrogen compound biosynthetic process, response to toxic substances (Supplementary Files 2 and 3; hsa04110_cellcycle; hsa04115_p53; hsa05034_alcoholism). Furthermore, qRTPCR analysis validated selected genes showing differential gene expression upon microarray analysis including GDF15, PPEF1, PLCH1, PLCD3, NNAT, MYC, ABCB1, CAMTA1, ABCC1, ABCG2, COX2, S100A6, ITPR1, ITPR3, and RYR3 (Supplementary Files 4 and 5).

\section{Combinations of pharmacological modulators of calcium signaling with CDDP or TOPO enhance cytotoxicity}

To assess a synergistic potential of pharmacologically targeting selected proteins involved in $\left[\mathrm{Ca}^{2+}\right]_{\mathrm{i}}$ regulation alongside conventional chemotherapy, we analyzed the viability of neuroblastoma cells following application of calcium signaling modulators alone or in combination with either CDDP or TOPO. Thapsigargin (THAPS), a sarco/endoplasmic reticulum $\mathrm{Ca}^{2+}$ ATPase (SERCA) pump inhibitor, evoked the largest cytotoxic effect of all investigated calcium signaling modulators when applied as single agent at a concentration of $0.2 \mu \mathrm{M}$. This effect was more pronounced in IMR-32 compared to SH-SY5Y cells (Figure 6A). Co-administration with either CDDP or TOPO significantly enhanced cytotoxicity in IMR-32 cells (but not SH-SY5Y cells) compared to single application of either drug (Figure 6A).

Treatment of SH-SY5Y with cyclosporine A (CYCLA) also had a significant cytotoxic effect. 
Table 1: The percentage of neuroblastoma cells responsive to chemotherapeutic drugs via an increase in $\left[\mathrm{Ca}^{2+}\right]_{i}$ is concentration dependent

\begin{tabular}{cccccc}
\hline Cell Type & Drug & Concentration $(\boldsymbol{\mu M})$ & Total Cells $(\boldsymbol{n})$ & Selected Cells $(\boldsymbol{n})$ & Cells analyzed $(\boldsymbol{\%})$ \\
\hline SH-SY5Y & CDDP & $\mathbf{0 . 0 0 1}$ & 44 & 17 & 38.64 \\
& & $\mathbf{0 . 0 1}$ & 52 & 40 & 76.92 \\
& & $\mathbf{0 . 1}$ & 52 & 48 & 92.31 \\
SH-SY5Y & $\mathbf{1}$ & 62 & 50 & 80.65 \\
& TOPO & $\mathbf{0 . 0 1}$ & 27 & 22 & 81.48 \\
& & $\mathbf{0 . 1}$ & 53 & 37 & 69.81 \\
IMR-32 & $\mathbf{1}$ & 42 & 31 & 73.81 \\
& $\mathbf{C D D P}$ & $\mathbf{0 . 0 0 1}$ & 40 & 19 & 47.50 \\
& & $\mathbf{0 . 0 1}$ & 22 & 13 & 59.09 \\
& & $\mathbf{0 . 1}$ & 38 & 30 & 78.95 \\
IMR-32 & $\mathbf{1}$ & 36 & 25 & 69.44 \\
& TOPO & $\mathbf{0 . 0 0 1}$ & 29 & 6 & 20.69 \\
& & $\mathbf{0 . 0 1}$ & 46 & 26 & 56.52 \\
& & $\mathbf{0 . 1}$ & 23 & 11 & 47.83 \\
& & $\mathbf{1}$ & 45 & 29 & 64.44 \\
\hline
\end{tabular}

The total and responding numbers of cells were recorded within a selected microscopic field for each experiment and the percentage of responsive cells (\%) was calculated following exposure to increasing concentrations of either CDDP or TOPO.

Furthermore, when CYCLA was combined with CDDP and applied to SH-SY5Y an enhanced cytotoxic effect was observed $(p<0.001)$ that was reproducible in IMR-32 cells for combinatory treatment with CYCLA and CDDP but also for CYCLA and TOPO (Figure 6B).

A similar result was found for dantrolene (DANTR), a ryanodine receptor antagonist (Figure 6C). 2-APB, an IP3 receptor antagonist, also was effective in reducing cell survival in combination with either CDDP or TOPO in IMR-32 cells but not in SH-SY5Y cells (Figure 6D). In addition, the membrane-permeable calcium chelator BAPTA-AM $(2 \mu \mathrm{M})$ was able to enhance cytotoxicity when given in combination with CDDP or TOPO in SHSY5Y and IMR-32 cells (Figure 6E). Results of further experiments using additional calcium signaling modulators and an additional neuroblastoma cell line (NLF cells) are provided as supplementary information (Supplementary Figures 5-8).

\section{DISCUSSION}

Neuroblastoma (NB), the most common extracranial solid tumor in children, is stratified into five stages $(1,2,3,4$ and 4S), two of which (3 and 4) identify a highly aggressive disease [15]. High-risk NB have been previously associated with distinct genomic alterations including mutations or rearrangements of $A L K, A T R X$, and TERT, as well as amplification of $M Y C N$ [14]. These and other molecular aberrations may reduce susceptibility to chemotherapy-induced programmed cell death (drug resistance) and thus are key factors in the treatment failure of advanced NB patients [15]. Primary and acquired drug resistance may lead to survival of tumor cells following chemotherapy and thereby trigger tumor recurrence and metastasis formation in neuroblastoma [2]. Therefore, finding alternative strategies to promote apoptosis or other types of programmed cell death pathways in response to treatment is relevant for the clinical management of aggressive forms of NB [15]. Since calcium signaling is a key factor in triggering cellular processes (e.g. differentiation, apoptosis, proliferation) [7, 16], we focused on its role in modulating response to CDDP and TOPO treatment of NB cells in vitro.

CDDP and TOPO are part of the pharmacological regimen for treatment of advanced neuroblastoma. CDDP is a chemotherapeutic drug used for several human malignancies and cytotoxicity is primarily mediated by its ability to cause DNA damage and subsequent apoptotic cell death [17-18,6]. Other reports suggested that CDDP may directly interact with mitochondria to induce apoptosis, and this may account for a significant part of its clinical activity [18]. In contrast, the cytotoxicity of TOPO, a topoisomerase I inhibitor, is reportedly due to a ternary complex of topoisomerase I, DNA and TOPO that interferes with the moving replication fork and eventually leads to a replication arrest and the formation of cytotoxic double-stranded breaks in the DNA [19]. Despite evidence of a role for calcium signaling in the therapeutic success 

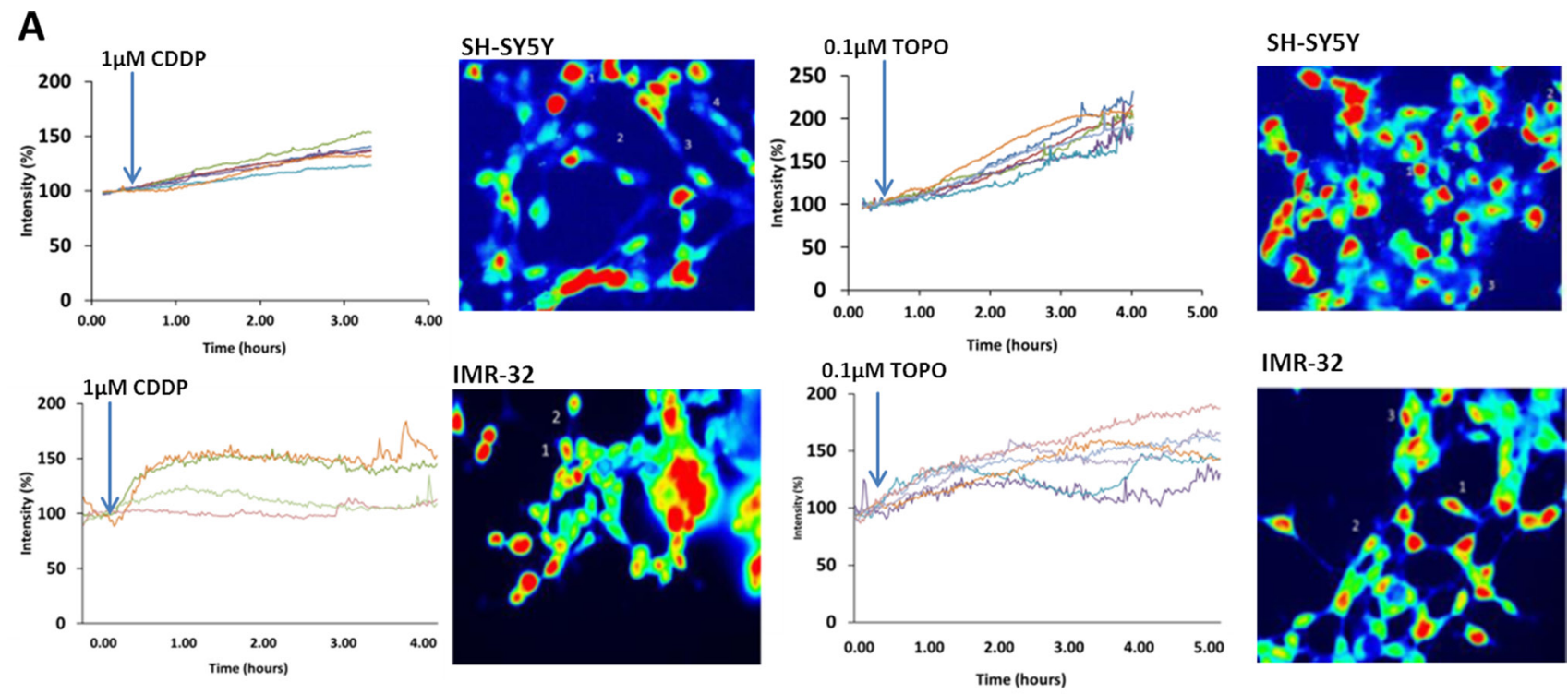

B

\section{SH-SY5Y}
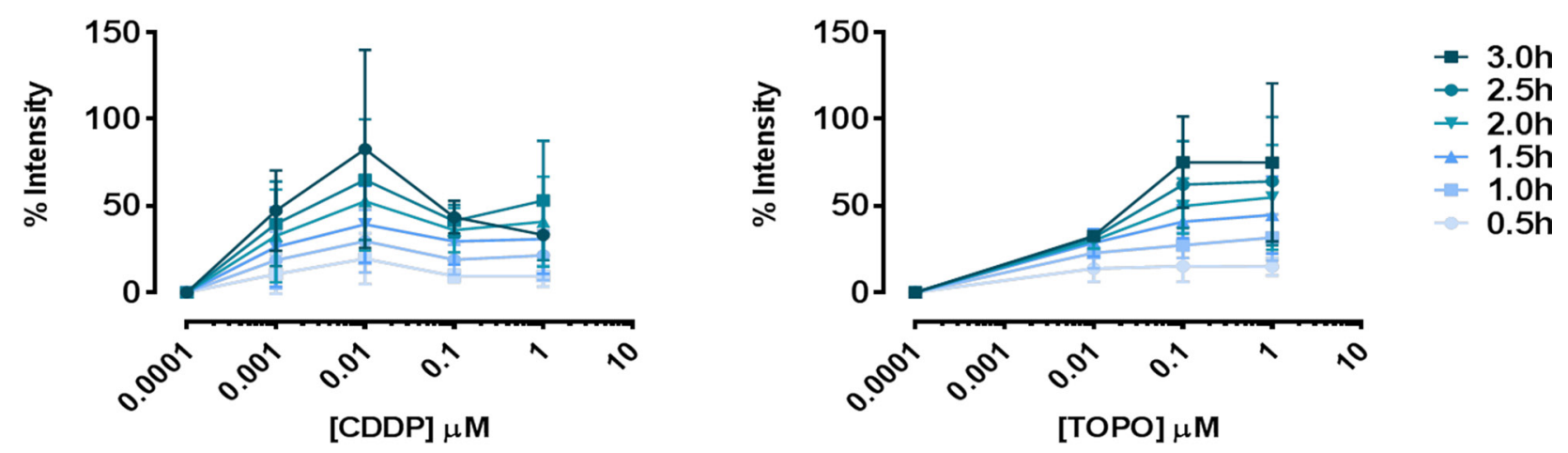

IMR-32

IMR-32
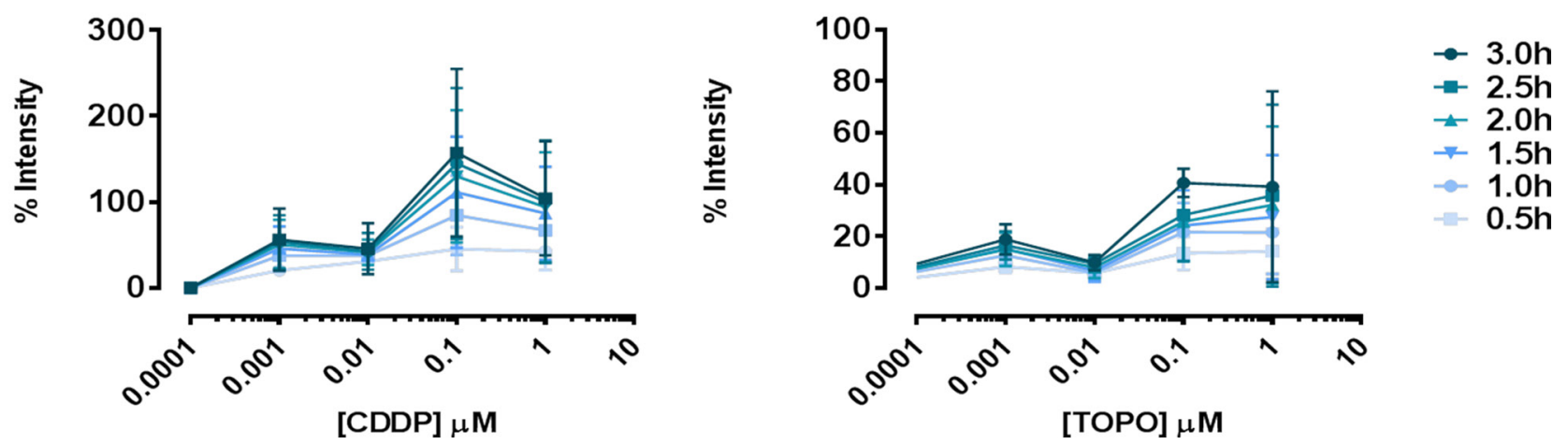

Figure 2: CDDP or TOPO treatment of neuroblastoma cells induces changes in $\left[\mathrm{Ca}^{2+}\right]_{i}$ in a time- and concentrationdependent manner. (A) Representative examples of increasing fluorescence intensity in individually selected cells following drug addition alongside corresponding images displaying subtracted cell fluorescence, highlighting accumulated calcium over 1-4 hours in SH-SY5Y and IMR-32 cells. (B) Increasing fluorescence intensity over a range of $0.5 \mathrm{~h}$ time points $(0.5 \mathrm{~h}-3.0 \mathrm{~h})$ following exposure to increasing concentrations of CDDP $(0.001-1 \mu \mathrm{M})$ or TOPO $(0.0001-1 \mu \mathrm{M})$ in SH-SY5Y and IMR-32 cells, expressed as percentage intensity relative to untreated fluorescence levels (\% intensity) (shown are results of three independent experiments at each time point and drug concentration). Two-way ANOVA statistical testing indicates significant variance that is both time- and concentration-dependent, $p<0.001\left({ }^{* * *}\right)$ as shown in the Supplementary Table: "Statistics Figure 2B". 
of these drugs, the underlying mechanisms have yet to be fully elucidated.

Data presented here demonstrate that relatively low concentrations of CDDP and TOPO can significantly reduce survival of NB cells in a time- and concentrationdependent manner. This effect is triggered mainly by an apoptotic pathway that activates effector caspases, though necrosis-mediated cell death is prominent following exposure to higher concentrations of CDDP or TOPO. Compared to CDDP, TOPO treatment resulted in more pronounced cell necrosis in our experiments. A role of $\left[\mathrm{Ca}^{2+}\right]_{\mathrm{i}}$ in both apoptotic and necrotic cell death has been reported [15]. In apoptosis, fluctuations in storedependent $\mathrm{Ca}^{2+}$ release mediated by IP3 receptors can induce prolonged endoplasmic reticulum (ER) stress and activation of pro-caspase-12, a precursor of effector caspases [20]. In necrosis, intracellular $\mathrm{Ca}^{2+}$ overload may trigger the activation of $\mathrm{Ca}^{2+}$-dependent proteases and a subsequent loss of cell membrane integrity [21]. Importantly, each neuroblastoma cell line exposed to CDDP or TOPO showed differences in intrinsic drug sensitivity, a finding in line with the observation of heterogeneity in neuroblastoma treatment response in patient studies [22].

Induction of apoptosis by CDDP has been shown to involve both caspase-dependent and caspase-independent apoptotic pathways [18] and has been linked to increased $\left[\mathrm{Ca}^{2+}\right]_{\mathrm{i}}[16]$; [5]. Our microarray-based gene expression profiling data demonstrated that CASP8 and CASP3 mRNA expression increased upon exposure of SH-SY5Y neuroblastoma cells to CDDP. We also investigated changes in $\left[\mathrm{Ca}^{2+}\right]_{\mathrm{i}}$ upon treatment of neuroblastoma cells
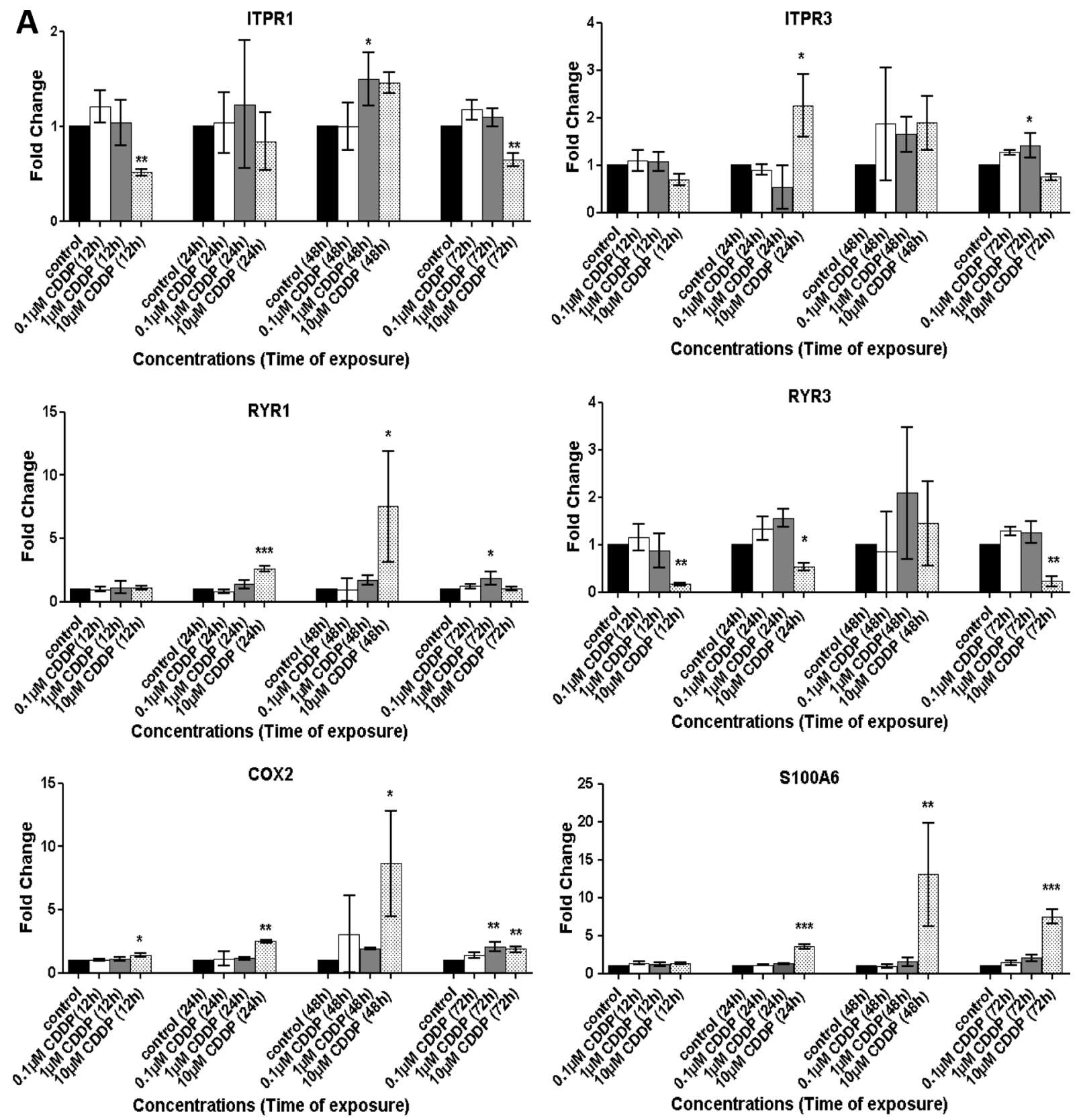

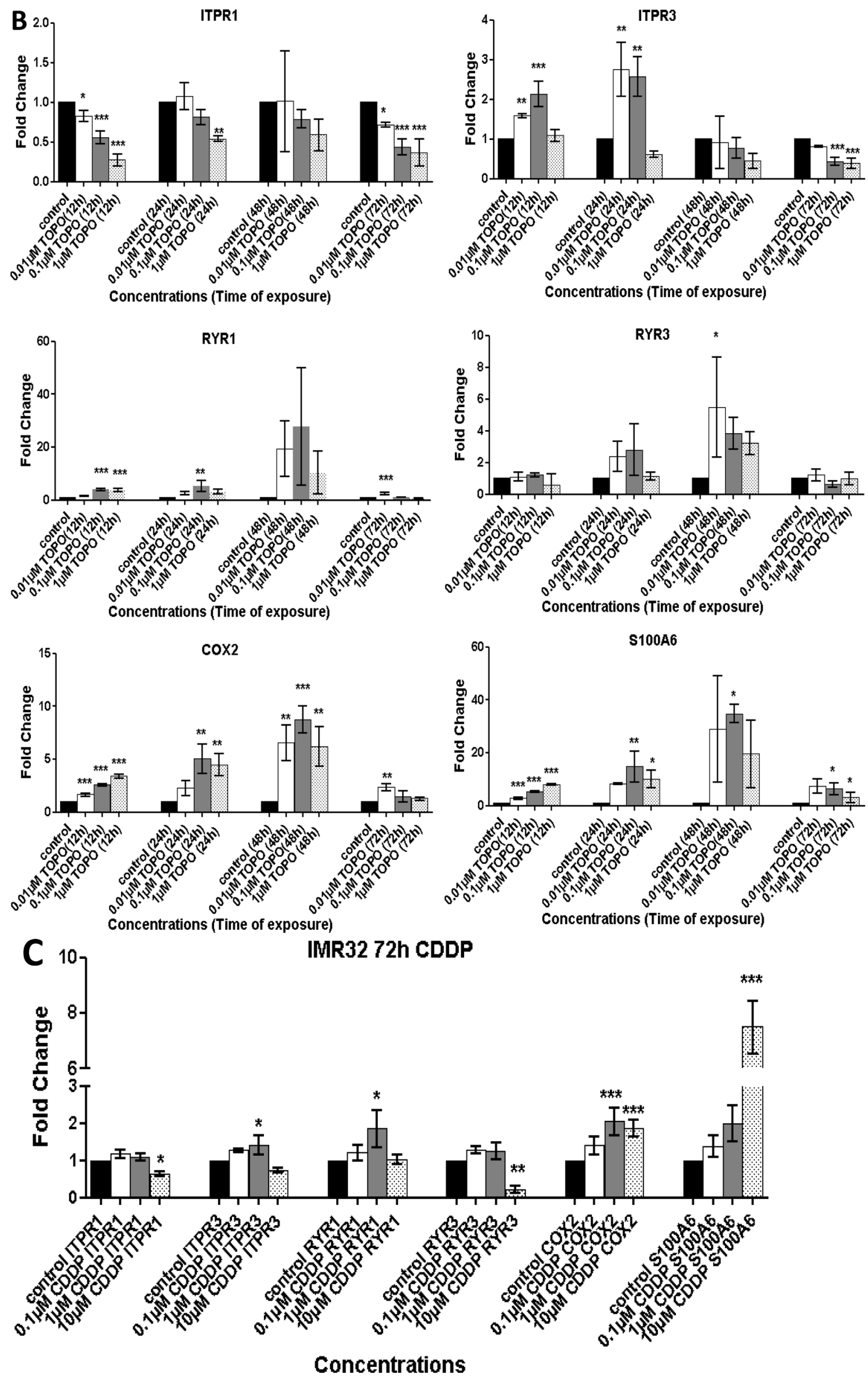
Figure 3: Treatment with CDDP or TOPO induces alterations in the mRNA expression of key $\left[\mathrm{Ca}^{2+}\right]_{\mathrm{i}}$ modulators in neuroblastoma cells. Changes in mRNA expression of ITPR1, ITPR3, RYR1, RYR3, S100A6 and COX2 were assessed via qRT-PCR in SH-SY5Y cells following $12 \mathrm{~h}, 24 \mathrm{~h}, 48 \mathrm{~h}$ or $72 \mathrm{~h}$ exposure to (A) $0.1 \mu \mathrm{M}-10 \mu \mathrm{M}$ CDDP or (B) $0.001 \mu \mathrm{M}-1 \mu \mathrm{M}$ TOPO. The expression pattern in IMR-32 cells was also assessed following exposure to $0.1 \mu \mathrm{M}-10 \mu \mathrm{M}$ CDDP (C). Data are expressed as fold-change (RQ), relative to the untreated control and are normalized to expression of $A R F-1$ mRNA as reference. Data are derived from three independent biological experiments each. Statistical significance is relative to the untreated control and considered if $p<0.05(*), p<0.01(* *)$, $p<0.001(* * *)$ as assessed by one-way ANOVA with Dunnett’s test for multiple comparisons.

A

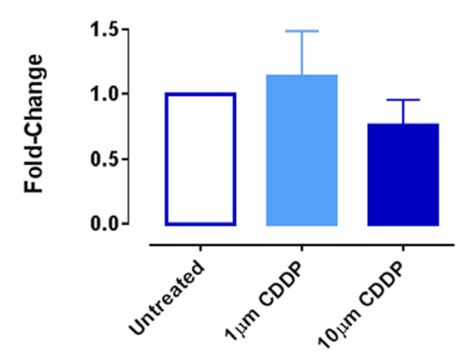

RYR1

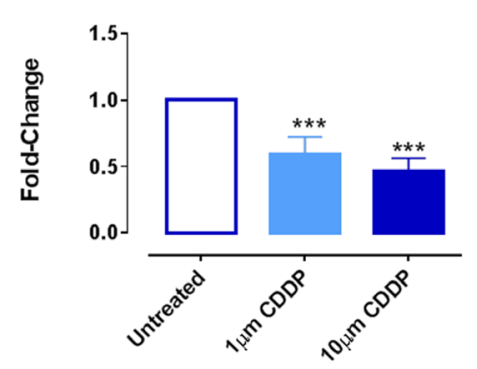

B
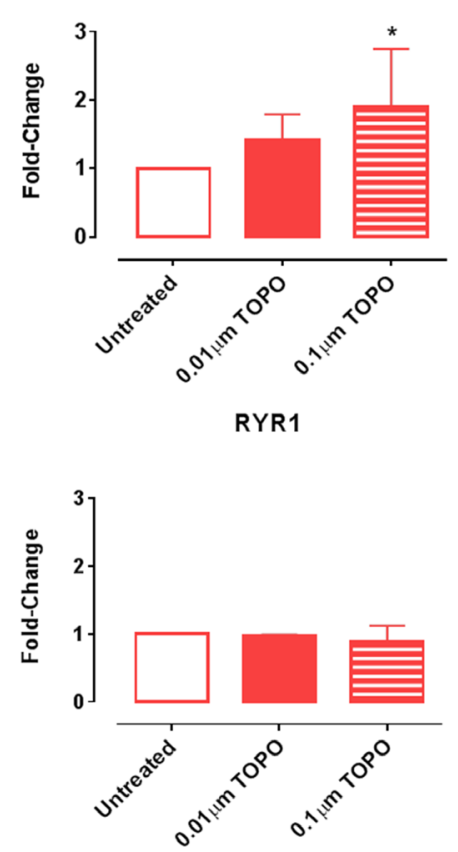
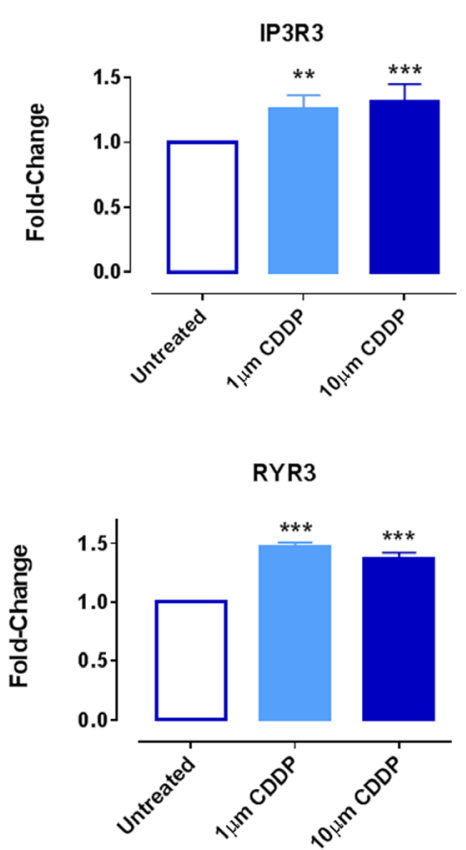

IP3R3

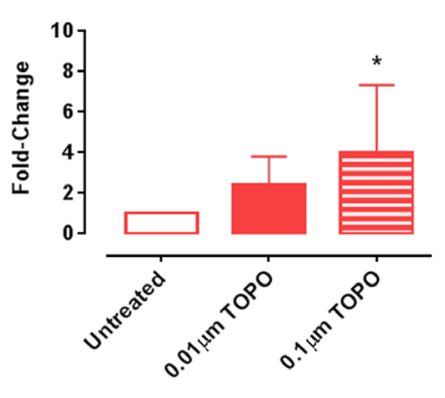

RYR3

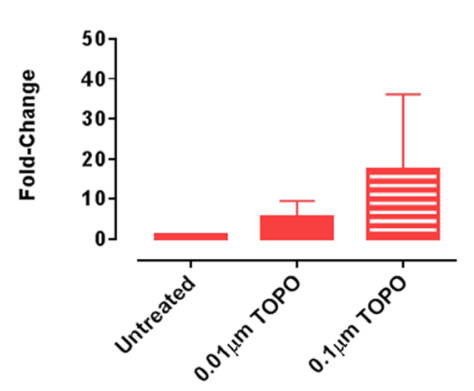

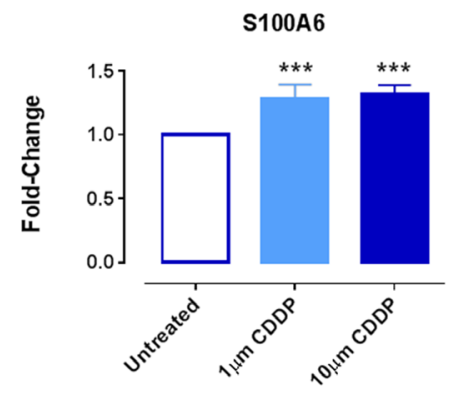

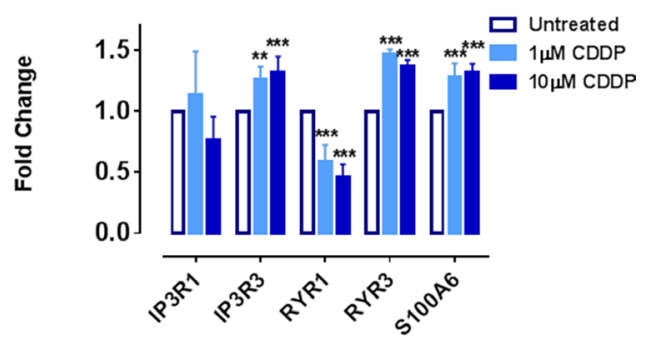

S100A6
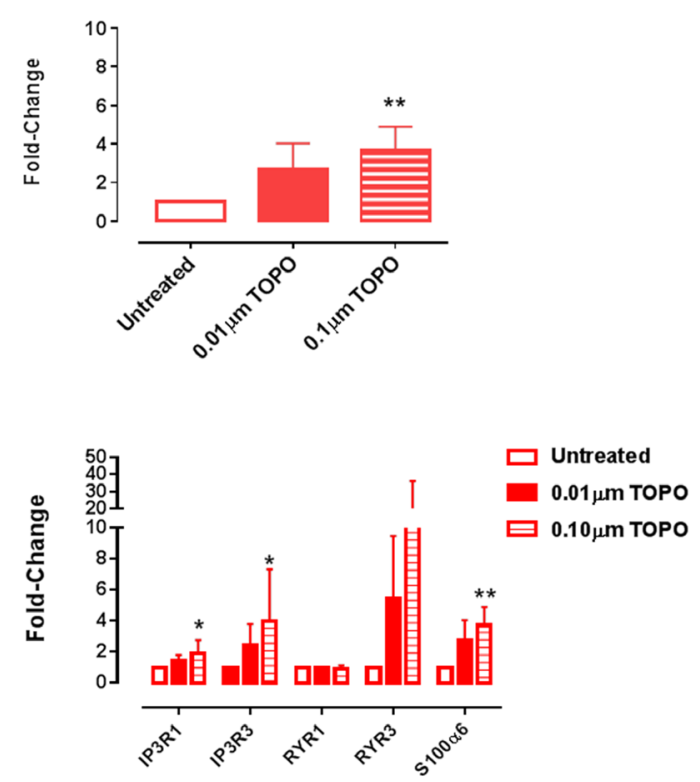

Figure 4: Changes in the expression of IP3R3, RYR3 and S100A6 at the protein level in SH-SY5Y cells following exposure to CDDP or TOPO. SH-SY5Y cells were treated with either (A) CDDP $(1 \mu \mathrm{M} / 10 \mu \mathrm{M})$ or (B) TOPO $(0.01 \mu \mathrm{M} / 0.1 \mu \mathrm{M})$ for 72 hours and then harvested, fixed, permeabilized and incubated with primary antibodies specific for IP3R1, IP3R3, RYR1, RYR3 or S100A6 followed by incubation with a fluorescently conjugated (Alexa-488 $\mathrm{nm}$ ) secondary antibody. The percentage of positive cells is individually presented for each protein or together for comparative analysis (expressed as a fold-change, relative to the untreated control). Data are derived from three independent biological experiments each. Statistical significance was calculated relative to untreated cells and considered if $p<0.01(* *)$ or $p<0.001(* * *)$ as assessed by a one-way ANOVA with Dunnett's test for multiple comparisons. 
Table 2: Fold-change in protein expression levels of $\mathrm{Ca}^{2+}$ regulatory proteins IP3R, RYR and S100A6 in SH-SY5Y cells

\begin{tabular}{|c|c|c|c|c|}
\hline \multicolumn{2}{|c|}{$1 \mu \mathrm{M}$ CDDP Fold-change } & & 1.24 & \\
\hline IP3R1 & 1.09 & $* *$ & 1.93 & $* *$ \\
\hline IP3R3 & 1.79 & $* * *$ & 2.6 & $* * *$ \\
\hline RYR1 & 2.13 & & 1.93 & \\
\hline RYR3 & 1.90 & $*$ & 2.41 & $*$ \\
\hline
\end{tabular}

Quantification of protein expression (fluorescence intensity/confocal microscopy) of IP3R1, IP3R3, RYR1, RYR3 or S100A6 following exposure to either $1 \mu \mathrm{M}$ CDDP or $0.01 \mu \mathrm{M}$ TOPO for $72 \mathrm{~h}$, expressed as a fold-change, relative to untreated cells. Statistical significance is relative to untreated cells and considered if $p<0.05(*), p<0.01(* *)$ or $p<0.001$ (***), assessed via Student's $T$-test.
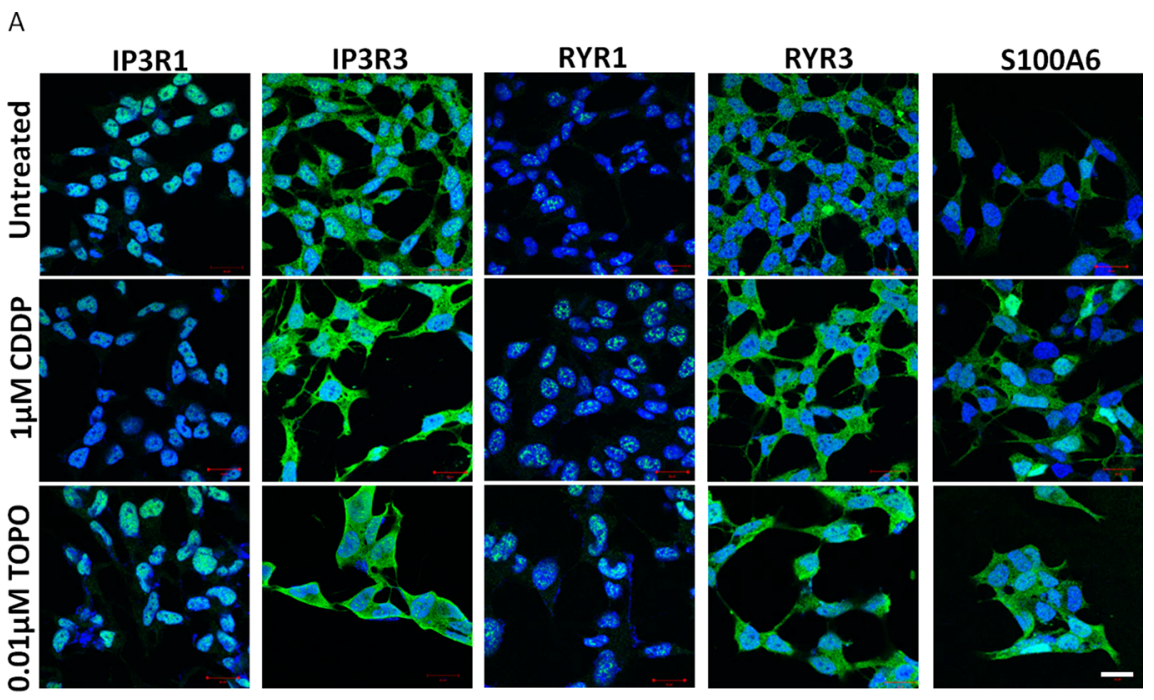

B
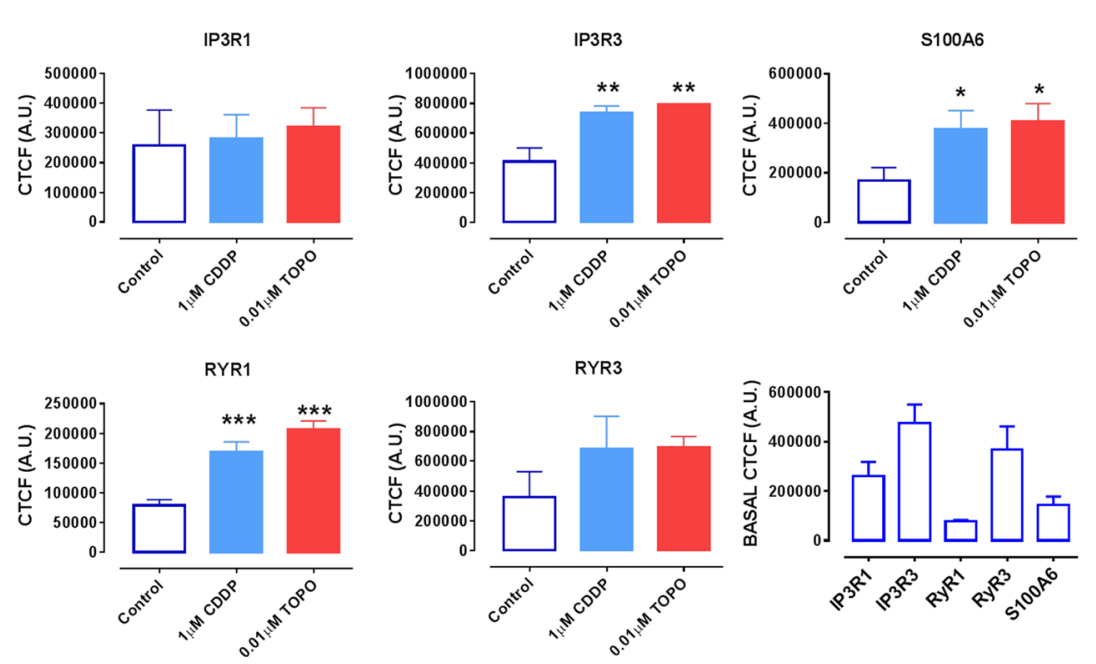

Figure 5: Confocal laser scanning microscopy demonstrates increased expression levels of IP3R3, RYR1 and S100A6 in SH-SY5Y cells following CDDP or TOPO treatment. (A) Representative fluorescence confocal images of SH-SY5Y cells that endogenously express IP3R1, IP3R3, RYR1, RYR3 and S100A6 as detected by Fluo-488 nm conjugated antibodies (green fluorescence) using images taken in similar experimental set ups following exposure to either $1 \mu \mathrm{M}$ CDDP or $0.01 \mu \mathrm{M}$ TOPO for $72 \mathrm{~h}$. Cell nuclei are counterstained with DAPI (blue). scale bar $=20 \mu \mathrm{m}$. (B) Quantification of fluorescence intensity (protein expression) expressed as mean corrected total cell fluorescence $(\mathrm{CTCF}) \pm$ standard deviation (SD). Data are derived from three independent biological experiments each. Statistical significance is relative to untreated cells and considered if $p<0.05(*), p<0.01(* *)$ or $p<0.001(* * *)$ as assessed by a one-way ANOVA with Dunnett's test for multiple comparisons. 
with CDDP or TOPO. In line with previous reports, we found a time- and concentration-dependent increase of $\left[\mathrm{Ca}^{2+}\right]_{\mathrm{i}}$ with either drug. Splettstoesser et al. [5] reported that CDDP increases $\left[\mathrm{Ca}^{2+}\right]_{i}$ time- and concentrationdependently in HeLa-S3 but not in U2-OS cells. The increase of $\left[\mathrm{Ca}^{2+}\right]_{i}$ was related to the activation of calpain, rather than caspase-8, triggering apoptosis (See Supplementary Files) [5]. Data from our cytotoxicity and $\left[\mathrm{Ca}^{2+}\right]_{\mathrm{i}}$ assay studies suggest that CDDP- or TOPOinduced cell death of SH-SY5Y and IMR-32 cells may also be caspase-independent at higher drug concentrations.

Although we were unable to directly assess the contribution of intracellular $\mathrm{Ca}^{2+}$ release following CDDP induction without promoting a stress-response via the omission of an external $\mathrm{Ca}^{2+}$ source (Supplementary
Figure 10), our previous investigations showed that IP3 receptor-regulated $\mathrm{Ca}^{2+}$-release governs CDDP-mediated apoptosis in cancer cells [5]. Whilst increases in $\left[\mathrm{Ca}^{2+}\right]_{\mathrm{i}}$ following exposure to CDDP or topotecan are both timeand concentration-sensitive in either neuroblastoma cell line, it was evident that the relationship is more linear in SH-SY5Y than in IMR-32 cells. We can speculate that the non-linear response exhibited in IMR-32 cells might be indicative of differential sources of calcium entry or release. We demonstrate that IMR-32 cells display higher sensitivity to the calcium antagonists thapsigargin, 2-APB and dantrolene when compared with SH-SY5Ys in cell survival assays. This might be suggestive of preferential intracellular calcium release in IMR-32 cells.
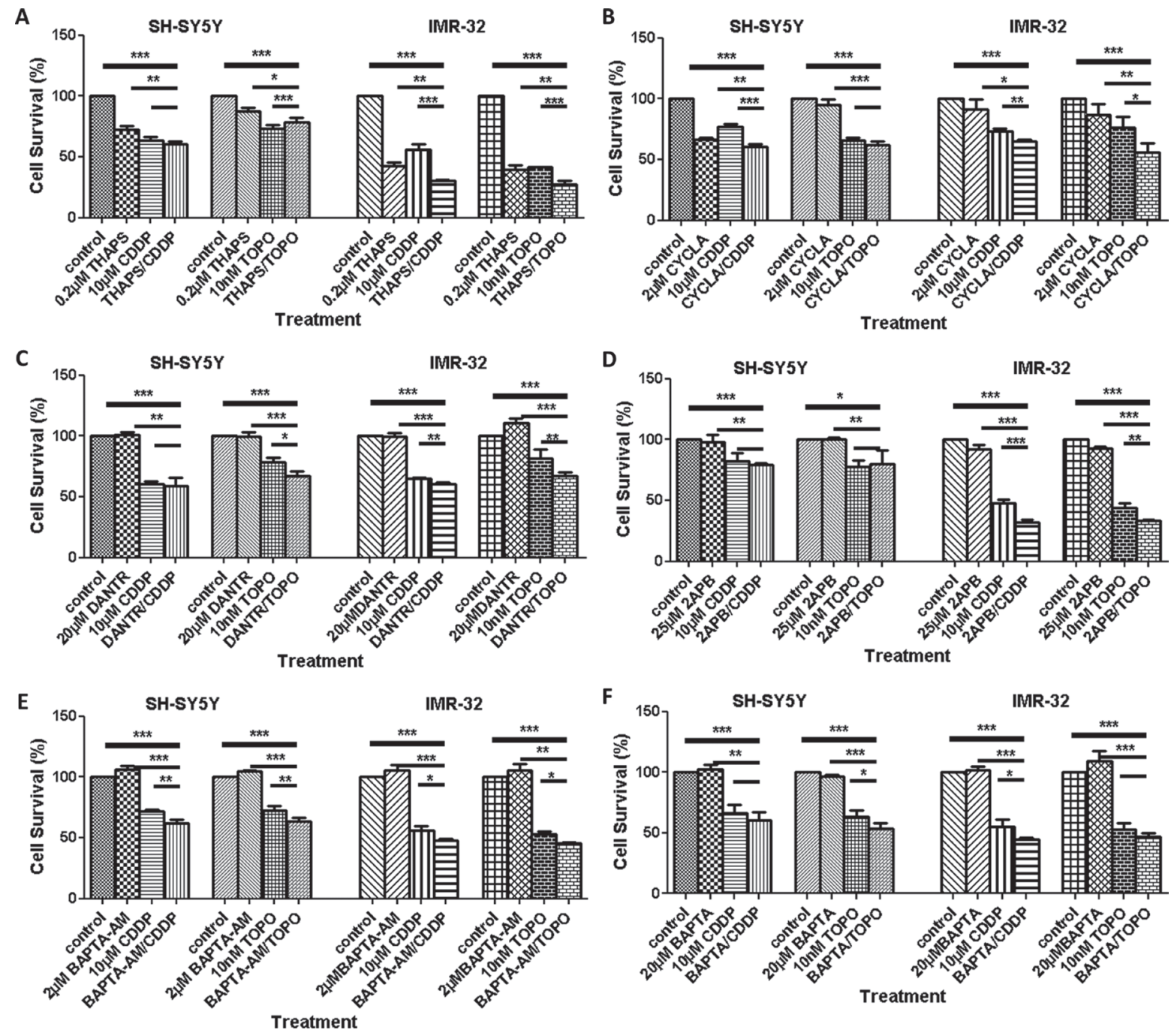

Figure 6: Viability of neuroblastoma cells treated with different types of calcium modulators alone or in combination with CDDP or TOPO. Sensitivity to calcium modulators alone or in combination with CDDP or TOPO was assessed in SH-SY5Y and IMR-32 human neuroblastoma cells using the trypan blue exclusion test after $72 \mathrm{~h}$ of drug exposure. The following pharmacological calcium modulators were applied: (A) thapsigargin (THAPS), (B) cyclosporine (CYCLA), (C) datrolene (DANTR), (D) 2-APB, (E) BAPTA-AM and (F) BAPTA. Data are based on three independent biological experiments and represent mean cell viability (\%) relative to control cells \pm standard deviation. Statistical significance is relative to the untreated control and considered if $p<0.05(*), p<0.01(* *)$, $p<0.001(* * *)$ and were assessed via a One-Way ANOVA with Dunnett's Test for multiple comparisons. 
Here, we focused on changes in the expression and function of selected proteins involved in calcium homeostasis following chemotherapy and explored whether combinatorial treatment of neuroblastoma cells with calcium modulators and CDDP or TOPO results in synergistic effects as indicated by increased cytotoxicity. In addition, we investigated whether chemotherapy alters mRNA and protein expression of key regulators involved in $\left[\mathrm{Ca}^{2+}\right]_{\mathrm{i}}$ homeostasis including the calcium-binding protein S100A6 (calcyclin), the inositol trisphosphate receptors 1 and 3 (ITPR 1 and ITPR3), as well as the ryanodine receptors 1 and 3 (RYR 1 and $R Y R 3$ ). COX2 expression was investigated to check for mitochondrial stress [23] known to occur upon exposure to anticancer drugs. The selected genes were found to be differentially expressed in the neuroblastoma cell lines following treatment. Most prominently, ITPR3 and RYR1 were consistently up-regulated at the mRNA and protein level following CDDP exposure in SH-SY5Y cells, suggesting a key role for the governance of intracellular calcium dynamics preceding chemotherapy-induced cell death, and this was paralleled by an up-regulation of $C O X 2$ mRNA levels. However, it is important to note that basal expression of RYR1 was initially very low in SHSY5Y cells and FACS analysis may be less sensitive in detecting changes in its expression. In this instance, it resulted in either no change in expression following exposure to TOPO, or negative expression for CDDP. In all neuroblastoma cell lines tested, expression of S100A6 was significantly up-regulated following exposure to either drug. The S100 gene family shares a common structure containing a $\mathrm{Ca}^{2+}$-binding EF-hand motif mediating the formation of protein-protein interactions with effector molecules. S100 proteins play key roles in various processes including differentiation, cytoskeleton dynamics, enzyme activity, $\mathrm{Ca}^{2+}$ homeostasis, cell growth as well as cell survival and apoptosis [24]. S100A6 expression has been associated with protection from TNF- $\alpha$-induced apoptosis in cardiomyocytes [25], decreased metastasis rate in cancer of the bone [26], as well as the regulation of cell cycle progression [27]. Furthermore, S100A6 induces epithelial-mesenchymal transition and promotes cell migration and invasion in a $\beta$-catenin-dependent manner [28]. We speculate that the increased expression of S100A6 following exposure to anticancer drugs demonstrated in our study may indicate a protective role for this protein in neuroblastoma cells and thus suggest this protein as a potential therapeutic target for combined chemotherapy strategies. Indeed, previous studies proposed S100A6 as potential therapeutic target in pancreatic cancer [28] and gastric cancer [29].

Treatment of SH-SY5Y cells for $72 \mathrm{~h}$ with CDDP deregulated the mRNA expression of several genes whose gene products are involved in calcium signaling as well as p53 signaling, cell cycle, apoptosis, histone- related epigenetic changes, metabolism and response to a toxic substance. These signaling pathways include many components that might be activated upon calcium increase [42] (e.g. cell cycle, p53), might be triggered by a calcium overload (e.g. apoptosis), or might take a role in buffering of the $\left[\mathrm{Ca}^{2+}\right]_{i}$ overloads. Thus, $\left[\mathrm{Ca}^{2+}\right]_{\mathrm{i}}$ changes observed upon exposure of neuroblastoma cells to CDDP might be able to disturb important signaling pathways that in turn might change global mRNA expression. In addition, previous work showed that CDDP also influences the expression of miRNAs, such as hsa-miR-204 [30], hsamiR-21 [31] and hsa-miR-16 [32].

As we observed treatment-related changes in $\left[\mathrm{Ca}^{2+}\right]_{\mathrm{i}}$ and in expression of several genes encoding modulators of calcium signaling, we also investigated whether treatment of neuroblastoma cells with pharmacological modulators of calcium-regulatory proteins may increase cytotoxic effects of CDDP and TOPO in neuroblastoma cell lines. Among the different pharmacological calcium modulators investigated, thapsigargin showed the highest cytotoxic effects. This compound is currently being assessed as a potential anticancer drug $[30,33]$. It is a strong inhibitor of sarco-endoplasmic reticulum $\mathrm{Ca}^{2+}$-ATP-ases (SERCA) and triggers store-operated $\mathrm{Ca}^{2+}$-entry [30, 31]. Upon depletion of the $\mathrm{ER} \mathrm{Ca}^{2+}$ stores, thapsigargin triggers the opening of plasma membrane $\mathrm{Ca}^{2+}$ channels and an ER stress response [33-35]. This is followed by activation of apoptotic pathways within the ER and the mitochondria. A sustained accumulation of $\mathrm{Ca}^{2+}$ in the mitochondrial matrix, induced by ER stress, might trigger the proapoptotic mitochondrial changes such as the permeability transition, dissipation of the electrochemical potential, matrix swelling, re-localization of Bax to mitochondria and the release of cytochrome $\mathrm{c}$ and other apoptosis-inducing factors [36]. Thereby, thapsigargin induces apoptosis, which could further enhance the apoptotic effects caused by conventional chemotherapeutics like CDDP or TOPO. Recently, analogues of thapsigargin have been developed for the treatment of prostate cancer and hepatocellular carcinoma [33]. Structure-activity relationships enabled design of equipotent analogues containing a linker coupled with peptides that are substrates for either prostate specific antigen (PSA) or prostate specific membrane antigen (PSMA), which enables specific targeting of the prodrug to prostate cancer cells and hepatocellular carcinoma cells. Results from a first phase I trial using a thapsigargin-based PSMA-activated prodrug in advanced solid cancers have been recently published $[33,37]$.

The second most toxic inhibitor of calciumregulatory proteins in neuroblastoma cells was cyclosporine A, a drug that is currently clinically used as an immunosuppressive agent [38, 39]. It targets calcineurin, resulting in a complete block of the translocation of the cytosolic component of the nuclear factor of activated $\mathrm{T}$ cells (NF-AT), consequently, resulting in a failure to activate genes regulated by the NF- 
AT transcription factor [40, 38]. In addition, cyclosporine A has been shown to induce mitochondrial permeability transition pore opening followed by reduction of delta psi $\mathrm{m}$ and caspase activation, thereby leading to apoptosis [41]. Therefore, cyclosporine A may lead to increased cytotoxicity when given in combination with CDDP or TOPO $[40,41]$.

A third calcium-regulatory compound with cytotoxicity in SH-SY5Y cells was 2-APB that blocks the function of IP3R [42]. Thus, long-time exposure to this compound might induce increased ER stress which in turn can induce cytotoxicity in neuroblastoma cells and increase the cytotoxic efficacy of CDDP or TOPO. Importantly, 2-APB has antagonistic effects on $\mathrm{Ca}^{2+}$-entry rather than $\mathrm{Ca}^{2+}$-release and modulates the store-operated $\mathrm{Ca}^{2+}$-entry [42]. Thus, our in vitro findings suggest that the three compounds discussed above or clinically tolerable derivatives of them may bear potential as anticancer drugs by fostering anti-cancer efficacy CDDP or TOPO. In addition, application of the RYR antagonist DANTR enhanced CDDP and TOPO cytotoxicity in IMR-32 cells, and CDDP toxicity in SH-SH5Y cells is likely due to increased ER stress as a result of long-time inhibition of RYRs that are normally required for the maintenance of cell function.

Finally, we investigated whether interfering with intra- or extra-cellular calcium can modulate the effectiveness of CDDP or TOPO treatment in neuroblastoma cells. Chelation of $\mathrm{Ca}^{2+}$ using membrane permeant BAPTA-AM enhanced cytotoxicity of both CDDP and TOPO indicating an induced stress response following a reduction in free intracellular calcium ions (Figure 6). Importantly, this is in agreement with reports of an upregulation in ER stress marker XBP1 in neuronal cell cultures following exposure to BAPTA-AM [43]. Furthermore, a partial chelation of extracellular calcium enhanced the effect in CDDP treatment in IMR-32 and NLF cells which cannot be explained in detail at this point, since more experiments will be required to elucidate the mechanisms of enhanced cytotoxicity due to regulation of $\left[\mathrm{Ca}^{2+}\right]_{i}$.

In conclusion, the treatment of cultured neuroblastoma cells with various concentrations of either CDDP or TOPO significantly decreased cell viability, increased apoptosis and increased $\left[\mathrm{Ca}^{2+}\right]_{\mathrm{i}}$ in a time- and concentration-dependent manner. Thus, deregulation of $\left[\mathrm{Ca}^{2+}\right]_{i}$ may contribute to the toxic effects of these chemotherapeutic agents. Moreover, expression of crucial regulators of calcium signaling, such as IP3R3, RYR3 and S100A6, are deregulated upon CDDP or TOPO treatment of neuroblastoma cells. Importantly, pharmacological modulation of the $\left[\mathrm{Ca}^{2+}\right]_{\mathrm{i}}$ response increased the cytotoxic effects of CDDP and TOPO in vitro, suggesting a potential role for combinatorial therapy in advanced neuroblastoma.

\section{MATERIALS AND METHODS}

\section{Chemicals}

The following chemicals of highest available purity were purchased from Tocris Biosciences, Bristol, Great Britain or R\&D, Germany: cisplatin (Cat. No. 2251), topotecan hydrochloride (Cat. No. 4562), thapsigargin (Cat. No. 1138), 2-aminoethoxydiphenylborane (2-APB, Cat. No. 1224), cylopiazonic acid (Cat. No. 0507), dantrolene (Cat. No. 0507), ryanodine (No. 1329), verapamil (Cat. No. 0654), nifedipine (Cat. No. 1075), 1,2-Bis(2-aminophenoxy) ethane-N,N,N',N'-tetraacetic acid (BAPTA, Cat. No. 2786), BAPTA-AM (Cat. No. 2787), and YM58483 (Cat. No. 3949).

\section{Cell culture and treatment schemes}

The SH-SY5Y (ATCC ${ }^{\circledR}$ CRL2266 ${ }^{\mathrm{TM}}$ ), IMR-32 $\left(\mathrm{ATCC}^{\circledR} \mathrm{CCL}^{\circledR 27^{\mathrm{TM}}}\right.$ ) neuroblastoma cell lines were obtained from American Type Culture Collection (ATCC, Manassas, Virginia). The NLF cell line was obtained from the CHOP cell line bank (Philadelphia, PA, USA). Neuroblastoma cells were maintained in culture as recommended by the provider. SH-SY5Y cells were grown in DMEM/F12 medium supplemented with $10 \%(\mathrm{v} / \mathrm{v})$ heat inactivated fetal bovine serum (FBS), penicillin (0.11U) and streptomycin $(100 \mu \mathrm{g} / \mathrm{mL})$; IMR-32 cells were grown in DMEM medium supplemented with $10 \% \mathrm{FBS}$, penicillin $(0.11 \mathrm{U})$ and streptomycin $(100 \mu \mathrm{g} / \mathrm{mL})$; NLF cells were grown in RPMI medium supplemented with $10 \% \mathrm{FBS}$, penicillin (0.11U) and streptomycin (100 $\mu \mathrm{g} / \mathrm{mL})$. All neuroblastoma cells were cultured under sterile conditions and were grown in a humidified incubator at $37^{\circ} \mathrm{C}$ with $95 \% \mathrm{O}_{2}$ and $5 \% \mathrm{CO}_{2}$.

\section{Trypan blue cytotoxicity test (TBCT)}

After exposure (12 h-72 h) to low concentrations of anticancer drugs (CDDP or TOPO at $0.1 \mathrm{nM}-10 \mu \mathrm{M}$ ) or calcium signaling modulators, the cells were trypsinized and collected in fresh culture medium, centrifuged at 2000 rpm for 5 minutes, resuspended in $500 \mu$ l complete culture medium and then analyzed using the TBCT test with a VICell XR cell analyzer (Beckmann Coulter, Germany) as recommended by the manufacturer.

\section{Apoptosis and cytotoxicity tests via fluorescence activated cell sorting (FACS)}

Total cytotoxicity and apoptosis were assessed using a kit with two fluorescent dyes, namely SR-FLICA (Fluorescent Labelled Inhibitors of Caspases) that covalently binds active caspase -3 and -7 enzymes, and 7-AAD that stains permeable necrotic cells (ImmunoChemistry Technologies, Bloomington, MN). Four types of cell 
population were quantified: 1) early apoptotic, 2) late apoptotic, 3) vital and 4) necrotic cell population. Cells were incubated with various concentrations of CDDP or TOPO for $72 \mathrm{~h}$. After drug incubation the cells were harvested and stained with SR-FLICA, followed by 7-AAD. After washing with PBS, fluorescence was acquired using the BD LSR Fortessa (BD Medical Technology) with 488nM laser for excitation and emission with two filters 585/15 and 610/20 for SR-FLICA and 7-AAD, respectively. Data were processed using FACSDiva 6.3. 50,000 events were recorded for each sample. Cells were sorted in four different types of cell population, indicated by four quadrants in the representative scatter plots.

\section{Live calcium imaging}

Cells were plated in $35 \mathrm{~mm}$ 'easy grip' BD Falcon tissue culture plates (Becton-Dickinson, USA). The plates were washed with Tyrode's buffer and loaded with Fluo-4AM ( $2 \mu \mathrm{M}$ final concentration) (Molecular Probes, USA), a calcium sensitive dye, for $45 \mathrm{~min}$ at $37^{\circ} \mathrm{C}$. Serial fluorescent images were taken with an Olympus Microscope BX51 Wi with Xenon Arc Burner and "Xcellence rt" software. An excitation wavelength of $494 \mathrm{~nm}$ and an emission wavelength of $516 \mathrm{~nm}$ were used. Images were taken every minute for up to $3.5 \mathrm{hrs}$. Cells were pre-defined via selected regions of interest (ROI) and the analysis was carried out offline. Results are expressed as percentage change in fluorescence intensity (\%) before and after drug application.

\section{Protein quantification via FACS}

For the quantification of protein expression, we utilized a flow cytometry-based technique that incorporates the use of monoclonal primary antibodies and fluorescently conjugated secondary antibodies for protein detection. This technique has been validated for intracellular and cell surface proteins and is relatively high-throughput $[42,44]$. Moreover, it has comparative sensitivity and specificity to other methods of protein quantification [45]. Monoclonal primary antibodies; IP3R1 (Ms, Santa Cruz), IP3R3 (Rb, Santa Cruz), RYR1 (Rb, Millipore), RYR3 (Rb, Millipore) and S100A6 (Rb, Ab Cam) detected protein expression in SH-SY5Y and IMR-32 cells fluorescently stained with alexa-488 conjugated secondary Ab (Life Technologies). This was analyzed by using the BD LSR Fortessa (BD Medical Technology). Fluorescence signals were acquired using a 488 Laser (530/30) FITC filter and 640 laser with APC 660/40. To exclude duplets, aggregates and debris, FSC/SSC gating was applied to an unstained control sample and single stained control samples were used to adjust the voltage of the photomultiplier tubes (PMTs) to generate a signal free from background fluorescence. Finally, fluorescence intensity was measured with respect to the unstained and isotype control and the data were analyzed using BD FACS Diva 6.3.

\section{Immunofluorescence imaging via confocal laser scanning microscopy}

SH-SY5Y cells were plated in 12-well plates before treatment with CDDP $(1 \mu \mathrm{M})$ or TOPO $(0.01 \mu \mathrm{M})$ for $72 \mathrm{~h}$. Then, cells were fixed in $4 \%$ paraformaldehyde (PFA) at $4^{\circ} \mathrm{C}$ and permeabilized using ice-cold $100 \%$ methanol. Non-specific antibody-binding was reduced by blocking with 5\% horse serum in PBS for 1 hour at room temperature. IP3R1, IP3R3, RYR1, RYR3 or S100A6 primary antibodies (as described for flow cytometry) in $5 \%$ horse serum at dilutions of 1 in 250 were used and a secondary alexa-488 conjugated antibody was applied. Coverslips were mounted using Prolong Gold antifade reagent with, and without, DAPI (Thermo Fisher Scientific). Images were acquired using a Carl Zeiss LSM-710 inverted confocal microscope (X63) with Zeiss Zen software. Fluorescence intensity was analyzed using Image J software and is expressed as 'corrected total cell fluorescence' (CTCF).

\section{Preparation of nucleic acids, cDNA synthesis and RT-PCR}

For extraction of RNA and DNA we used the AllPrep DNA/RNA Mini Kit (Qiagen, Hilden, Germany) following the provider's protocol. Extracted RNA was kept at $-80^{\circ} \mathrm{C}$ and was used for cDNA synthesis using the Superscript II Kit (Invitrogen, Carlsbad, California, USA). For mRNA analysis, specific primers were designed using the Primer3 software and oligonucleotides were purchased from Eurofins MWG (München, Germany). Prior to use, the primers were tested using Human Universal Reference RNA (Stratagene, San Diego, California, USA), which was used as interplate calibrator for the RT-PCR analyses. As reference, expression levels of 18s and ARF1 were initially tested and ARF1 transcript levels were used for the experiments presented in this manuscript using the 2(-DeltaDeltaCt) method. The following primers were used: ITPR1 F: TTCCATCCTAACGGAACGAG; ITPR1 R: CACTCTGTTGCCAAAGCAAG; ITPR3 F: ACTGC CTCTTCAAGGTGTGC; ITPR3 R: CCCATGCACCTTC TTGTTCT; RYR1 F: GTCATCCTGTTGGCCATCATC; RYR1 R: GGTCTCGGAGCTCACCAAAAG; RYR3 F: GGCCACAGGACCCTGTTAT; RYR3 R: CTGTGGCATG TTCCCGTAG; S100A6 F: GAAGGAGCTGAAGGAGCT GA S100A6 R: CCCTTGAGGGCTTCATTGTA 18S F: CG GCTACCACATCCAAGGAA; 18S R: GCTGGAATTAC CGCGGCT; ARF1 F: GACCACGATCCTCTACAAGC; ARF1 R: TCCCACACAGTGAAGCTGATG.

\section{Microarray analysis}

Three samples of parental SH-SY5Y cells and four samples of SH-SY5Y cells treated for $72 \mathrm{~h}$ with $10 \mu \mathrm{M}$ CDDP were subjected to microarray-based gene expression analyses. RNA quality was determined using 
the Agilent Bioanalyzer and the Eukaryote Total RNA Nano Chip (Agilent Technologies, Hayward, CA, USA). The RNA integrity number (RIN) was measured as 9.910. The Affymetrix HuGene 2.0 ST and WT plus reagent kit (Affymetrix, Santa Clara, California, United States) was used following the provider's recommendation with a start material of $100 \mathrm{ng}$ of total RNA. Affymetrix chip hybridizations were performed at the Center for Biological and Medical Research (BMFZ) at Heinrich Heine University Düsseldorf using a GeneChip Hybridization Oven 645 and a GeneChip ${ }^{\circledR}$ Scanner 3000 $7 \mathrm{G}$. Bioinformatic evaluation of the microarray data was done with the $\mathrm{R}$ framework for statistical computing. The dataset was normalized and log2-transformed using the robust multi-array average (RMA) method implemented in the affy package. Differential expression of mRNA was assessed by computing the moderated t-statistics using the LIMMA package. The resulting $p$-values were corrected for multiple testing by controlling the false discovery rate. A mRNA was considered as being differentially expressed when the corrected $p$-value was below 0.05 . For mapping of gene ontology terms and KEGG pathway terms the web interface RAMONA was used for the genes that showed a significant fold change (FC) in expression of $<$ 0.5 or $>0.5$ (Sass et al., 2015). The microarray data were submitted to the Gene Expression Omnibus repository (GEO); datasets are found under the GEO submission number GSE86842.

\section{Statistics}

Results are shown as means \pm standard deviation (SD). One-way ANOVA tests with Dunnett's test for multiple comparisons and Student' $t$-test were used to compare statistical differences between controls and each of the treatment groups and a two-way ANOVA test was used to interpret the statistical relationship between controls and treatment groups. $P$ values of $<0.05$ $(*),<0.01(* *)$ and $<0.001(* * *)$ were considered as statistically significant. Experiments were repeated on at least three independent occasions $(n=3-5)$ and analyzed using Microsoft Excel and GraphPad Prism 6 software.

\section{Supplementary material}

Supplementary figures and supplementary files are provided as online attachment.

\section{ACKNOWLEDGMENTS}

The authors would like to thank Safaa Shaheen and Noothan Jyothi Satheesh for their help and assistance with the FACS experiments for protein expression analysis. We thank the Flow Cytometry Facility within the Microscopy Core at Weill Cornell Medical College in Qatar for contributing to these studies. The Core is supported by the
"Biomedical Research Program at Weill Cornell Medical College in Qatar", a program funded by Qatar Foundation. We also would like to acknowledge the Genomics and Transcriptomics Core Facility at the Biological and Medical Research Center (BMFZ), Heinrich Heine University Düsseldorf, for performing the Affymetrix HuGene 2.0 ST chip hybridization and scanning.

\section{CONFLICTS OF INTEREST}

None.

\section{FUNDING}

This study was supported by NPRP grant \# 6-089-3021 from the Qatar National Research Fund (a member of Qatar Foundation). The statements made herein are solely the responsibility of the authors.

\section{REFERENCES}

1. Irwin MS, Park JR. Neuroblastoma Paradigm for Precision Medicine. Pediatric Clinics of North America, 2015; 62:225.

2. London WB, Castel V, Monclair T, Ambros PF, Pearson ADJ, Cohn, SL, Berthold F, Nakagawara A, Ladenstein, RL, Iehara T, Matthay KK. Clinical and Biologic Features Predictive of Survival After Relapse of Neuroblastoma: A Report From the International Neuroblastoma Risk Group Project. J Clin Oncol, 2011; 29:3286-3292.

3. Pearson $\mathrm{AD}$, Pinkerton $\mathrm{CR}$, Lewis IJ, Imeson J, Ellershaw C, Machin D. European Neuroblastoma Study Group; Children's Cancer and Leukaemia Group (CCLG formerly United Kingdom Children's Cancer Study Group). High-dose rapid and standard induction chemotherapy for patients aged over 1 year with stage 4 neuroblastoma: a randomised trial. Lancet Oncol. 2008; 9:247-56.

4. London WB, Frantz CN, Campbell LA, Seeger RC, Brumback BA, Cohn SL, Matthay KK, Castleberry RP, Diller L. Phase II randomized comparison of topotecan plus cyclophosphamide versus topotecan alone in children with recurrent or refractory neuroblastoma: a Children's Oncology Group study. J Clin Oncol. 2010; 28:3808-15.

5. Splettstoesser F, Florea AM, Büsselberg D. IP(3) receptor antagonist, 2-APB, attenuates cisplatin induced $\mathrm{Ca}^{2+}$-influx in HeLa-S3 cells and prevents activation of calpain and induction of apoptosis. Br J Pharmacol. 2007; 151:1176-86.

6. Florea AM, Büsselberg D. Cisplatin as an anti-tumor drug: cellular mechanisms of activity, drug resistance and induced side effects. Cancers (Basel). 2011; 3:1351-71.

7. Satheesh NJ, Büsselberg D. The role of intracellular calcium for the development and treatment of neuroblastoma. Cancers (Basel). 2015; 7:823-48.

8. Florea AM, Splettstoesser F, Büsselberg D. Arsenic trioxide (As2O3) induced calcium signals and cytotoxicity in 
two human cell lines: SY-SY5Y neuroblastoma and 293 embryonic kidney (HEK). Toxicol Appl Pharmacol. 2007; 220:292-301.

9. Florea AM, Büsselberg D. Arsenic trioxide in environmentally and clinically relevant concentrations interacts with calcium homeostasis and induces cell type specific cell death in tumor and non-tumor cells. Toxicol Lett. 2008; 179:34-42.

10. Florea AM, Büsselberg D. Anti-cancer drugs interfere with intracellular calcium signaling. Neurotoxicology. 2009; 30:803-10.

11. Günes DA, Florea AM, Splettstoesser F, Büsselberg D. Coapplication of arsenic trioxide (As2O3) and cisplatin (CDDP) on human SY-5Y neuroblastoma cells has differential effects on the intracellular calcium concentration $\left([\mathrm{Ca} 2+]_{\mathrm{i}}\right)$ and cytotoxicity. Neurotoxicology. 2009; 30:194-202.

12. Chen QR, Song YK, Wei JS, Bilke S, Asgharzadeh S, Seeger RC, Khan J. An integrated cross-platform prognosis study on neuroblastoma patients. Genomics. 2008; 92:195-203.

13. Guo X, Chen QR, Song YK, Wei JS, Khan J. Exon array analysis reveals neuroblastoma tumors have distinct alternative splicing patterns according to stage and $\mathrm{MYCN}$ amplification status. BMC Med Genomics. 2011; 4:35.

14. Sass S, Pitea A, Unger K, Hess J, Mueller NS, Theis FJ. MicroRNA-Target Network Inference and Local Network Enrichment Analysis Identify Two microRNA Clusters with Distinct Functions in Head and Neck Squamous Cell Carcinoma. Int J Mol Sci. 2015; 16:30204-22.

15. Nicolai S, Pieraccioli M, Peschiaroli A, Melino G, Raschellà G. Neuroblastoma: oncogenic mechanisms and therapeutic exploitation of necroptosis. Cell Death Dis. 2015; 6:e2010.

16. Zhivotovsky B, Orrenius S. Defects in the apoptotic machinery of cancer cells: role in drug resistance. Semin Cancer Biol. 2003; 13:125-34.

17. Al-Taweel N, Varghese E, Florea AM, Büsselberg D. Cisplatin (CDDP) triggers cell death of MCF-7 cells following disruption of intracellular calcium $\left(\left[\mathrm{Ca}\left({ }^{2+}\right)\right]_{\mathrm{i}}\right)$ homeostasis. J Toxicol Sci. 2014; 39:765-74.

18. Santin G, Piccolini VM, Veneroni P, Barni S, Bernocchi G, Bottone MG. Different patterns of apoptosis in response to cisplatin in B50 neuroblastoma rat cells. Histol Histopathol. $2011 ; 26: 831-42$.

19. Musa F, Blank S, Muggia F. A pharmacokinetic evaluation of topotecan as a cervical cancer therapy. Expert Opin Drug Metab Toxicol. 2013; 9:215-24.

20. Ferri KF, Kroemer G. Organelle-specific initiation of cell death pathways. Nat Cell Biol. 2001; 3:E255-63.

21. Ricci MS, Zong WX. Chemotherapeutic approaches for targeting cell death pathways. Oncologist. 2006; 11:342-57.

22. Weinstein JL, Katzenstein HM, Cohn SL. Advances in the diagnosis and treatment of neuroblastoma. Oncologist. 2003; 8:278-92.

23. Weinberg JB. Nitric oxide synthase 2 and cyclooxygenase 2 interactions in inflammation. Immunol Res. 2000; 22:319-41.
24. Emberley ED, Murphy LC, Watson PH S100 proteins and their influence on pro-survival pathways in cancer. Biochem Cell Biol. 2004; 82:508-15.

25. Tsoporis JN, Izhar S, Parker TG. Expression of S100A6 in cardiac myocytes limits apoptosis induced by tumor necrosis factor-alpha. J Biol Chem. 2008; 283:30174-83.

26. Luu HH, Zhou L, Haydon RC, Deyrup AT, Montag AG, Huo D, Heck R, Heizmann CW, Peabody TD, Simon MA, He TC. Increased expression of S100A6 is associated with decreased metastasis and inhibition of cell migration and anchorage independent growth in human osteosarcoma. Cancer Lett. 2005; 229:135-48.

27. Leśniak W, Słomnicki ŁP, Filipek A. S100A6 - new facts and features. Biochem Biophys Res Commun. 2009; 390:1087-92.

28. Chen X, Liu X, Lang H, Zhang S, Luo Y, Zhang J. S100 calcium-binding protein A6 promotes epithelialmesenchymal transition through $\beta$-catenin in pancreatic cancer cell line. PLoS One. 2015; 10:e0121319.

29. Zhang J, Zhang K, Jiang X, Zhang J. S100A6 as a potential serum prognostic biomarker and therapeutic target in gastric cancer. Dig Dis Sci. 2014; 59:2136-44.

30. Ryan J, Tivnan A, Fay J, Bryan K, Meehan M, Creevey L, Lynch J, Bray IM, O’Meara A, Tracey L, Davidoff AM, Stallings RL. MicroRNA-204 increases sensitivity of neuroblastoma cells to cisplatin and is associated with a favourable clinical outcome. Br J Cancer. 2012; 107:967-76.

31. Chen Y, Tsai YH, Fang Y, Tseng SH. Micro-RNA-21 regulates the sensitivity to cisplatin in human neuroblastoma cells. J Pediatr Surg. 2012; 47:1797-805.

32. Sun YX, Yang J, Wang PY, Li YJ, Xie SY, Sun RP. Cisplatin regulates SH-SY5Y cell growth through downregulation of BDNF via miR-16. Oncol Rep. 2013; 30:2343-9.

33. Quynh Doan NT, Christensen SB. Thapsigargin, Origin, Chemistry, Structure-Activity Relationships and Prodrug Development. Curr Pharm Des. 2015; 21:5501-17.

34. Christensen SB, Skytte DM, Denmeade SR, Dionne C, Møller JV, Nissen P, Isaacs JT. A Trojan horse in drug development: targeting of thapsigargins towards prostate cancer cells. Anticancer Agents Med Chem. 2009; 9:276-94.

35. Foufelle F, Fromenty B. Role of endoplasmic reticulum stress in drug-induced toxicity. Pharmacol Res Perspect. 2016; 4:e00211.

36. Deniaud A, Sharaf el dein O, Maillier E, Poncet D, Kroemer G, Lemaire C, Brenner C. Endoplasmic reticulum stress induces calcium-dependent permeability transition, mitochondrial outer membrane permeabilization and apoptosis. Oncogene. 2008; 27:285-99.

37. Mahalingam D, Wilding G, Denmeade S, Sarantopoulas J, Cosgrove D, Cetnar J, Azad N, Bruce J, Kurman M, Allgood VE, Carducci M. Mipsagargin, a novel thapsigarginbased PSMA-activated prodrug: results of a first-in-man phase I clinical trial in patients with refractory, advanced or metastatic solid tumours. Br J Cancer. 2016; 114:986-94. 
38. Levy RA, de Jesús GR, de Jesús NR, Klumb EM. Critical review of the current recommendations for the treatment of systemic inflammatory rheumatic diseases during pregnancy and lactation. Autoimmun Rev. 2016; 15:955-63.

39. Guada M, Beloqui A, Kumar MN, Préat V, Dios-Viéitez Mdel C, Blanco-Prieto MJ. Reformulating cyclosporine A (CsA): More than just a life cycle management strategy. J Control Release. 2016; 225:269-82.

40. Ho S, Clipstone N, Timmermann L, Northrop J, Graef I, Fiorentino D, Nourse J, Crabtree GR. The mechanism of action of cyclosporin A and FK506. Clin Immunol Immunopathol. 1996; 80:S40-5.

41. Sohn HW, Choi EY, Kim SH, Lee IS, Chung DH, Sung UA, Hwang DH, Cho SS, Jun BH, Jang JJ, Chi JG, Park SH. Engagement of CD99 induces apoptosis through a calcineurin-independent pathway in Ewing's sarcoma cells. Am J Pathol. 1998; 153:1937-45.
42. Bootman MD, Collins TJ, Mackenzie L, Roderick HL, Berridge MJ, Peppiatt CM. 2-aminoethoxydiphenyl borate (2-APB) is a reliable blocker of store-operated $\mathrm{Ca}^{2+}$ entry but an inconsistent inhibitor of InsP3-induced $\mathrm{Ca}^{2+}$ release. FASEB J. 2002; 16:1145-50.

43. Paschen W, Hotop S, Aufenberg C. Loading neurons with BAPTA-AM acti-vates $\mathrm{xbp} 1$ processing indicative of induction of endoplasmic reticulum stress. Cell Calcium. 2003; 33:83-89.

44. Bourdin B, Segura E, Tetreault MP, Lesage S, Parent L. Determination of the relative cell surface and total expression of recombinant ion channels using flow cytometry. J Vis Exp. 2016; 115:e54732.

45. He L, Fox M. Comparison of flow cytometry and western blotting to measure Hsp70. Cytometry. 1996; 25:280-6. 